
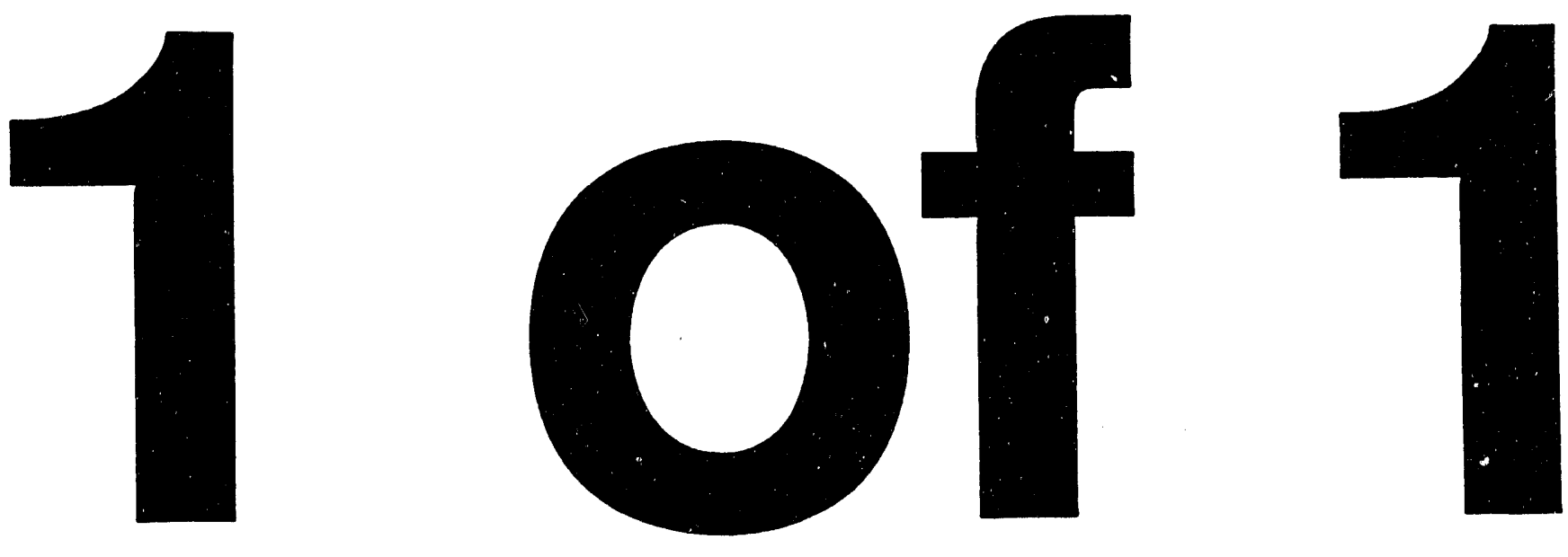


\section{U.S. House of Representatives Committee on Energy and Commerce Subcommittee on Energy and Power}

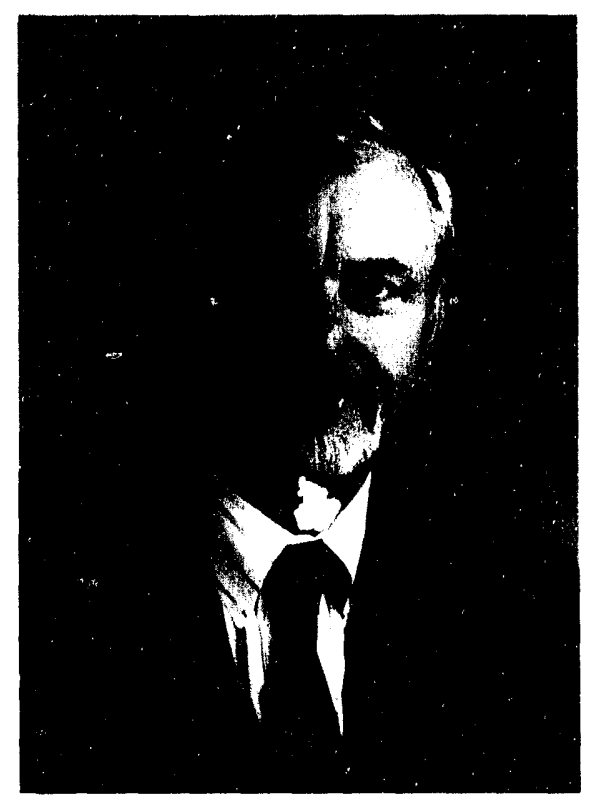

\section{Introduction}

Chairman Sharp and distinguished members of the Committee, I am Albert Narath, president and director of Sandia National Laboratories. Sandia, as you know, is a multiprogram laboratory of the Department of Energy (DOE). It carries out scientific research and technology development for the DOE and other agencies in support of mission responsibilities that range from defense to economic competitiveness. It is managed and operated by Martin Marietta Corporation, which took over that responsibility from AT\&T on October 1, 1993.

I welcome this opportunity to share with you my views on the role of the Department of Energy multiprogram laboratories during this transformational period in national needs and priorities. I have testified on this important topic on two previous occasions: before the Senate Energy and Natural Resources Committee on March 18 (concerning Senate Bill 473) and before the House Science, Space, and Technology Committee, Energy Research and Development Subcommittee on March 23 (concerning House Resolution 1432). At the Senate hearing I endorsed Senate Bill 473 and expressed my appreciation for the efforts of Senator Bingaman and Senator Domenici for introducing legislation that significantly broadens the mission of the DOE National laboratorias. Subsequently, Sandia vice president C. Paul Robinson presented testimony on my behalf to the House

\section{MASTER}

Science, Space, and Technology Committee on July 29 concerning H.R. 1432. These statements document Sandia's position on this important matter. I would also like to thank Congressman Bill Richardson for introducing House Resolution 2875, DOE National Competitiveness Technology Partnership Act, which is the subject of today's hearing. The statement I am submitting for the record of our hearing today is consistent with these earlier statements and provides additional information.

My views on this issue have been shaped not only by my 30 years at Sandia National Laboratories, but also by my five years as a vice president at AT\&T Bell Laboratories immediately following the breakup of the Bell System. It was there that I learned some important facts about competition in the industrial world. I learned that technical excellence alone is not sufficient to achieve success in the marketplace. I also learned that even the most competent organization cannot be best at everything and that partnerships and teamwork are often essential business strategies.

\section{The Convergence of the Defense and Civilian Technology Bases}

There can be no question that the DOE multiprogram laboratories possess world-class facilities and technical talent. Throughout their half century of existence, these laboratories have played key roles in supporting the 
Department's R\&D mission responsibilities in nuclear weapons, energy, environment, and basic science. Although the distribution of effort among these topics has shifted somewhat in recent times, and will presumably continue to do so, they represent enduring responsibilities. In pursuing these responsibilities, the laboratories have made substantial contributions to national security in its several aspects.

A comprehensive definition of national security must include national defense, energy security, environmental integrity, and economic vitality. These four elements are tightly interrelated and cannot be realized separately. National defense requires a robust industrial base; economic vitality requires secure and affordable energy supplies; energy usage and manufacturing processes must be environmentally benign for economic growth to be sustainable.

The technology bases that support these four elements of national security are largely congruent. This has been amply demonstrated over the last twenty years at the three DOE Defense Program laboratories, where a multidisciplinary set of core competencies, originally developed for the nuclear-weapon mission, now also supports, and is supported by, a variety of programs in energy, environment, and industrial competitiveness. Neither the government nor industry can support separate industrial bases for defense and civilian applications. Consequently, these industrial sectors are merging and their constituent capabilities are more broadly shared.

\section{Technology Leadership}

Leadership in technology is a crucial factor, although not the only factor, in ensuring national security in this broad sense - national defense, energy security, environmental integrity, and economic vitality. The necessity of technology leadership for defense is obvious: U.S. military superiority exploits continuously advancing technologies for superior offensive and defensive systems. But technology leadership is also vital for the nation's economic security, which requires continuous advancement of product and manufacturing technologies to sustain superior productivity. Technology leadership both derives from and supports a robust, integrated high-technology industrial base.

But we need to go beyond national security, even in this broader sense, and conceive a vision of greater national well-being. By "national well-being" I am not invoking a laudable but intangible idealism. Progress in national well-being ought to be objectively measurable by metrics such as employment levels; renewal of public infrastructure; efficiency of resource consumption; public health and safety, life expectancy, and literacy; environmental quality; and even national solvency. National well-being requires the accumulation and perpetual renewal of national wealth. The investment of that wealth into programs to improve national well-being is the result of policy decisions made in the public and private sectors. But if our pool of national wealth diminishes and is not continuously renewed, national wellbeing by all these measures will suffer.

It is for this reason that national economic competitiveness is so important. High levels of national prosperity are dependent on domestic industries that can compete effectively in the global marketplace. An integrated approach to technology research and application development that injects the results of scientific discovery into the product development cycle can be an accelerating factor in the competitiveness equation. It is here that the federal goverument has a legitimate role and, indeed an obligation, to provide science and technology assistance to U.S. industry.

\section{The Government/Industry Relationship in Science and Technology}

Unfortunately, there still exists no clear consensus on when and ho'v government should assist industry and how government/industry collaboration should be implemented. But first, we should acknowledge that government and industry are de facto partners in science and technology, and have been so for more than fifty years. This partnership has typically taken the form of acquisition programs that have fostered certain industries and various interventions that have sometimes succeeded and sometimes failed. The essential role of government in advancing basic science has also been recognized for a long time. The policy question at this stage is whether the government/industry relationship should be more systematic. Is there an optimum vehicle or structure of collaboration that should be institutionalized? To what extent should such collaborations extend to technology commercialization?

It is perhaps not surprising that industry, universities, and federally funded research and development institutions all see themselves as the best candidate for a leadership role in a new architecture of collaboration for the private and public sectors. Industry quite rightly insists that research and development partnerships must be market-driven if they are to be prudent uses of resources, and it sees itself as the best interpreter of market opportunities. The university research community quite rightly stresses its historic role of advancing knowledge and making seminal contributions to many technologies. Moreover, universities are frequently very aggressive in pursuing commercialization of the fruits of their research, often in partnership with private firms. Federally funded research and development institutions vary widely in their missions and capabilities. However, speaking from the perspective of the large, multiprogram laboratories of the Department of Energy, I believe these institutions can point to unique performance characteristics that differ from those in industry and academia. The DOE laboratories can draw from broad, multidisciplinary competencies to develop integrated systems approaches to large, complex, long- 
lived national problems. Such work often involves a degree of risk greater than what industry can normally accept, including great technical uncertainties, large investment in facilities, and long lead times. Particularly in basic research, the laboratories often perform work that requires sustained, managed effort on a substantial scale and extending over many years. Moreover, the disinterested position of the DOE laboratories enables them to furnish objective advice to the government in matters of science and technology and the management of scientific endeavors.

By acknowledging the particular strengths of these groups - industry, universities, and the DOE multiprogram laboratories - perhaps we can agree that the diversity of their performance attributes and organizational cultures is a source of strength. The magnitude, complexity, and urgency of the competitiveness challenge facing our nation are so great that only through teamwork and partnership among all sectors of our nation's science and technology enterprise, including full cooperation among federal agencies, can we hope to be successful. These camps must not regard each other as competitors; rather, they should embrace a vision of partnership for solving the nation's most pressing problems.

That vision has recently been articulated in a draft strategic plan by the Department of Energy entitled "Partnerships for Global Competitiveness." Developed under the leadership of Secretary O'Leary with wide participation from the DOE community, the plan is a bold statement of intent to more broadly incorporate industry and universities into DOE programs. While it is true that the multiprogram laboratories have a long history of successful collaboration with the private sector, particularly in programs of applied research, the plan calls for going much farther:

Our goal must be to get the maximum value for the American public out of the budget made available to the Department. This means that every dollar spent toward meeting the Department's missions - whether for basic research, nuclear weapons stewardship, environmental cleanup, or energy production and conservation - must be examined for its potential to be leveraged toward a mutual benefit with industry, academia, or other agencies.

A continuing role certainly exists for direct grants to industry and universities for research or technology development. I would not expect that role to diminish. It is critically important, however, to achieve a balance between direct grants to industries and universities on the one hand and federal funding for industrial partnerships involving the national laboratories on the other. Generic, precompetitive research and development performed through partnerships involving the national laboratories, universities, and industry can have a multiplier impact on jobs and industry market share because of its broad representation and participation.

All institutions, both private and public, should strive to improve their performance. We in the DOE laboratories are very much aware of this obligation and are taking concrete steps to continuously improve our performance. But I question whether a radical restructuring of the DOE laboratory community at this time will result either in improved performance or better value for the taxpayers' dollar.

A national laboratory is more than a collection of facilities and people with technical skills. The creative synergy of a multiprogram laboratory environment is established over time and is the result of relationships among technical core competencies that are exercised for the benefit of sponsors' programs. Those competencies may be difficult to reconstruct in another environment or at another time. Consequently, I urge you to exercise caution as you evaluate proposals for changing or restructuring the DOE laboratories.

\section{Laboratory Effectiveness: A Historical Example}

The truly important question in my view is: What actions or policies will make the laboratories most effective in addressing national needs in areas that can benefit from their particular competencies? I want to stress that this is not a plea for employment security. Rather, I take it as a given that the enormous investment of public funds that created these institutions should not be wasted. Perhaps we should begin to answer the question by looking closely at an organization that is widely acknowledged as having been one of the most successful mission-oriented laboratories in history: Bell Telephone Laboratories (BTL) comprised a broad spectrum of science and technology activities, including very speculative, long-range scientific research, technology development and demonstration, and an aggressive program of product development. Since its inception, it had strong ties to industry, most directly to AT\&T's manufacturing arm, the Western Electric Co.

During the decades following the Second World War and prior to the divestiture of the Bell operating companies, BTL operated in an environment very similar to that of the national laboratories at that time. It was assured of stable, long-term support from a governmentregulated monopoly. Although signifi 'nt contributions were made by various industrial, university, and federal laboratories, BTL was in large measure the driving force behind the scientific discoveries and technological innovations that have created the emerging information age. Those innovations include the transistor, digital transmission, fiber-optic communications, and manufacturing-technology advances in the fabrication of solid-state electronic devices.

Today, the success of pre-divestiture BTL provides a striking demonstration of how a large, vertically integrated, internally directed $R \& D$ laboratory, strongly interacting with academic institutions and exchanging 
technical information freely with industry, can bring about technical revolutions. This is the model we should emulate in our national laboratories.

\section{Sandia's Evolution}

\section{to a Multiprogram Laboratory}

Sandia was strongly influenced by the BTL model during the 44 years it was managed by AT\&T. But prior to 1970 , activities were almost exclusively focused on our nuclear weapons mission. Our role included, among other responsibilities, design and integration of components for nuclear warheads and interactions with the manufacturing sector of the nuclear weapons complex to turn them into manufactured products.

There is a widespread misperception that the DOE. Defense Programs laboratories are just now beginning to diversify beyond nuclear weapons activities. In fact, for Sandia this process began twenty years ago; it began even earlier for Los Alamos and lawrence Livermore national laboratories. In 1974, the OPEC oil embargo forced a painful recognition of the extent of U.S. energy dependency on imported oil. The Atomic Energy Commission and a few other agencies were reorganized into the Energy Research and Development Administration (ERDA). The Atomic Energy Commission laboratories possessed capabilities that were readily applicable to research in improved energy conversion and utilization. Sandia's mission, along with that of the other national laboratories, was expanded to meet this challenge. It has been documented ${ }^{1}$ that the federal investment in energy technology research and development at the laboratories generated savings of many billions of dollars for industry and consumers and provided improved technologies for industry to exploit.

The new energy mission came at a crucial time for Sandia. A steady decline in nuclear weapons work beginning in 1965 had necessitated a large reduction in the work force during 1972-73. More significantly, this decline was beginning to have a debilitating impact on Sandia's technical competencies and special capabilities that were then, as today, needed to support core mission responsibilities. The energy mission offered a means of preserving the Laboratories' technology base. 'The focus on long-term energy issues permitted program diversification and the reallocation of technical capabilities originally reserved for weapons programs. For example, the Combustion Research Facility, established at Sandia's California laboratory at that time, made use of the Laboratories' capability in laser diagnostics, which had been developed in the nuclear weapons program for gas dynamics studies. The facility has since become a designated DOE user facility and one of the earliest and most

\footnotetext{
l "The Role of Federal Research and Development in Advancing Energy Efficiency: A $\$ 50$ Billion Contribution to the U.S. Fconomy," Howard Geller, Jeffrey P. Harris, Mark D. Levine, Arthur H. Rosenfeld, in Ammual Review of Energy, Vol. 12, 1987. Jack M. Hollander, Ed., Annual Reviews, Inc., l'alo Alto.
}

successful examples of collaborative research involving a national laboratory, industry, and academia. As a percent of total laboratory activities, our nuclear weapons research, development, testing, and stockpile support programs have declined from approximately 90 percent of the laboratories' operating budget in the early 1970s to approximately 40 percent today. The remaining 60 percent of our work is distributed among other DOE, defense-related activities, DOE energy and environmental research and development, technology transfer programs, and work for other federal agencies that is closely related to our $\mathrm{DOE}$ mission responsibilities.

\section{Sandia's Energy Programs Today}

Today, Sandia is one of the nation's premier contributors to energy technology, particularly in renewable energy (such as solar, wind, and geothermal), fossil energy, and nuclear power. It is our goal to help improve both the supply and utilization sides of the energy equationwhile minimizing environmental impacts. We have strong ties to industry in all of our energy research and development work. We are especially proud of the integration of our environmental technologies program with our energy-related effort. This ensures that contributions in the energy area have passed the test of being environmentally conscious.

A prudent strategy for securing energy supply must be broad-based. In the long term, we can't really afford to ignore any energy supply option, including nuclear power. Currently, some of the most promising work on the supply side is in the area of oil and gas recovery and renewable energy systems.

Sandia, together with Los Alamos National Laboratory, is a major partner in DOE's Oil Recovery Technology Partnership. This partnership, which is led by industry, helps offset the massive disinvestment in research and development by the petroleum industry in the past several years. Through it, industry (including the independents, majors, and service companies) has access to national laboratory facilities, equipment, and expertise that might have near-term application in improved oil recovery processes. The laboratories have unique capabilities in electronics, instrumentation, materials, engineering, computer modeling, and geological science that can be usefully applied to the technology of oil recovery.

One of the original goals of the ()il Recovery lechnology Partnership is to provide assistance to independent oil producers who have been particularly hardhit by low oil prices, and we have worked directly with independent producers to improve their recovery techniques. Recently, we incorporated an Advanced Computational Initiative in the partnership to develop three-dimensional seismic simulation and reservoir characterization tools. These computational tools will help integrate the geological and engineering data required for the development of domestic gas and oil fields. 
We are also helping to develop advanced rock drilling systems for gas exploration and recovery. Among fossil fuel options, natural gas is an energy source of choice for many applications because of its clean burning characteristics.

In renewable energy, the trend is similarly toward joint ventures and consortia involving the industry and DOE. Renewable energy sources are an important part of the nation's energy mix for the long term. They are particularly promising for certain niche areas, such as distributed or remote utilities. While domestic utilization of renewable energy systems will remain small in relative terms for the foreseeable future, a significant international market opportunity exists for U.S. manufacturers. Renewable energy systems are often preferred sources of electric power for developing nations. However, system designs must be highly manufacturable and robust if they are to be competitive. Sandia's Photovoltaic Design Assistance Center has already helped U.S. manufacturers compete effectively in this emerging international market. Sandia's rich capability in manufacturing engineering and systems design brings an industrial focus to renewable energy research and development that is unmatched at any other DOE laboratory.

On the utilization side of the energy equation as well, Sandia is very active. Our capabilities in battery technology (which derive from our weapons work), materials, information-driven manufacturing, and combustion technology contribute to development work that can result in more efficient and environmentally clean energy utilization in transportation, buildings, and industrial processes.

At Sandia's Combustion Research Facility in California, we work closely with industry to increase the energy efficiency of internal combustion engines and industrial and residential furnaces. This activity is part of the DOE Office of Industrial Technology's Combustion Technology program sponsored by the Assistant Secretary for Energy Efficiency and Renewable Energy. Twenty years ago, long before the CRADA mechanism came into being, we devised an approach to cooperative $R \& l$ ) that we referred to as Cooperative Working Groups. As a means to optimize collaboration among the industrial, university, and national laboratory participants, this approach remains as effective today as it was then. Industry partners in these working groups have included General Motors, Ford Motor Company, Chrysler, Cummins Engine Company, Exxon, Navistar, Unocal, GRI, AGA, and Lennox Industries.

An instrumented head gasket for studying the combustion process in production engines was developed at our Combustion Research Facility in response to direct inquiries from industry. The gasket, which earned an R\&D 100 Award, incorporates ionization probes that detect the position of the flame in the cylinder, permitting measurement of combustion uniformity in an engine under development. The technology for this diagnostic gasket was transferred to a small business-DSP Technology, Inc. of Fremont, California - which now manufactures it. In another example, researchers at Sandia's Combustion Research Facility, working with engineers from lennox Industries, together produced an advanced pulse combustor design for use in residential and industrial furnaces. Pulse combustion leads to improved energy efficiency over conventional designs and provides a more competitive product.

Sandia is active with the United States Advanced Battery Consortium. The consortium is a partnership of Chrysler, Ford, and General Motors with the Electric Power Research Institute and some individual electric utilities. It was formed to research and develop rechargeable battery technologies for electric vehicles. Sandia's role grew out of its historic weapon-component development responsibilities. Our role in the automotive battery program is to conduct applied research and to perform tests to meet the objectives established by the industrial partners of the consortium. Those objectives include demonstrating production capability for a battery with a five-year life that could be produced in the late 1990s and, by 1994, a battery with a ten-year life that could go into production sometime after 2000 . Development of such batteries will help auto manufacturers meet the 1998 deadline set by several states for the introduction of electric vehicles. Technology developed under this cooperative research and development agreement will be available to the consortium and its licensees. The project will enhance the competitive position of the United States in battery and automotive markets and help assure a viable and competitive domestic battery industry.

I believe the DOE national laboratories also have much to contribute to the new-generation Clean Car initiative announced by the White House in September. This multi-agency initiative, led by the Department of Commerce, has ambitious goals for improving the efficiency of vehicles. Achieving those goals will require advances on multiple fronts, including new materials, agile manufacturing, battery development, and engine design. Confidence in Sandia's ability to make significant technical contributions to these efforts is attested by the substantial cooperative research and development agreements already in place between Sandia and automobile manufacturers. In many ways, our history of successful collaboration with industry in the development of energy technologies gave us a good foundation for today's enhanced laboratory missions in technology transfer and industrial competitiveness.

All of our applied energy programs have clearly traceable roots in core competencies that grew out of the nuclear-weapon program and continue to depend on that program for a major fraction of current funding. In recent years these competencies have also been strengthened by basic-energy-science support provided by DOE's Office of Energy Research (OER). The Combustion Research Facility, which contributes directly to DOE's 
energy goals, was created by OER and still receives essential support from OER for its basic science programs and for the development of advanced laser-based diagnostic tools. Geosciences and materials sciences support from OER has played an equally important role in ensuring the success of our oil and gas projects.

\section{Planning for a Changing Operating Environment}

During the late 1980s, there were clear signs of impending change that compelled Sandia's management to consider the future of the institution. Three developments converged to make this period stressful. First, revelations of environmentally unsafe practices in the nuclear weapons complex during the years of the cold war badly damaged public confidence in DOE and its laboratories. Second, all in-progress and planned nuclear weapon programs for new systems were either canceled or suspended, and a series of dramatic arms reduction agreements presaged a much smaller nuclear weapon program. Third, there was increasing concern over the apparent erosion of the nation's high-technology industrial base and its longterm impact on national security.

To help prepare for a future with diverse new challenges, Sandia established a formal strategic planning process in 1989. In early 1990, Sandia's first high-level strategic plan was developed, beginning a process of reassessment and cultural change throughout the organization. This strategic plan will soon be revised and updated to reflect the management philosophy of our new operating contractor, Martin Marietta Corporation, and to respond to trends that were not foreseen in the original plan.

As a subset of our first strategic planning effort, we embarked on an exercise to rigorously define the Laboratories' core competencies. Our core competencies are the distinguishing skills, capabilities, technologies, and facilities needed to perform the Laboratories' $\mathrm{DOE}$ missions. As such, they provide the basis for program selection in a multiprogram operating environment.

Our core competencies model is a matrix of supporting research foundations and applied integrated capabilities. The research foundations provide a technology base on which the Laboratories' integrated capabilities depend. They include: engineered processes and materials, computational and information sciences, microelectronics and photonics, and engineering sciences. Integrated capabilities made possible by these research foundations include: surety technology (to deliver products that meet the highest levels of safety, security, and control for nuclear weapons and other applications); experimental, computational, and analytical evaluation; advanced manufacturing technology (to meet the manufacturing needs of both the nuclear weapons complex and U.S. industry); pulsed power technology; and engineered systems.

Sandia's diversification has been organized around its core technical competencies. Programs must both strengthen our core competencies by exercising them and derive significant benefit from them to be appropriate for this laboratory. We plan our program mix with our cognizant agency sponsor as part of the Department of Energy's institutional planning process to achieve this compatibility.

In addition, in 1990 Sandia adopted Total Quality Management, as successfully pioneered in industry, as the operating paradigm for the Laboratories. Our guiding principles for implementing quality at Sandia are the Malcolm Baldrige National Quality Award criteria. We have embarked on internal initiatives to achieve progress in quality performance according to the Baldrige criteria. These efforts incorporate many of today's modern quality principles: continuous improvement, customer satisfaction, employee satisfaction, and quality by design.

Partially as a result of the self-examination that accompanies a commitment to quality, Sandia went through a corporate reorganization in 1991 that resulted in better alignment of management responsibilities with customer programmatic needs. This change was followed by a corporate restructuring that made the management organizational structure flatter and forced decision-making responsibility closer to the working level. I believe that these changes, and other changes to come, will make the laboratories more responsive to customer needs and requirements and a more agile and effective partrer with both government and industry.

\section{Sandia's Strategy for Enhancing Industrial Competitiveness}

Sandia's interactions with U.S. industry had their beginning in the weapon program. Mutually beneficial collaborations can be traced back to the 1950s. The invention of the Vertical Laminar Clean Room technology, and its subsequent adoption by hospitals, the micrnelectronics industry, etc. represents an early success of enormous impact. Today, Sandia's work in support of economic competitiveness permeates all of our programs. Its size and scope have increased over the past twenty years, and its funding is conservatively estimated at $\$ 132$ million in fiscal year 1994. This amount includes the DOE Defense Programs Technology Transfer Initiative, the DOE portion of other technology partnerships with industry, industry funds for joint research, our small business assistance program, and portions of our applied energy program that are directly attributable to cooperative work with industry for industry's benefit.

Sandia has a history of transferring technologies developed in weapons and energy programs to the civilian industrial sector that predates the legislative mandate for technology transfer by more than three decades. Long before technology transfer became a mission assigned to Sandia by the National Competitiveness " Technology Transfer Act of 1989, we learned that teamwork with industry, both in technology development and transfer, is a smart business practice that enhances 
our ability to meet our obligations.

We consider the use of our core competencies to help improve the U.S. economy to be a natural extension of our historic mission assignments. Moreover, effective collaboration among government, industry, and universities - the exchange of expertise and knowledgeenables the national laboratories to maintain the core competencies that make them important national assets and allows the private sector to leverage its research and development resources by taking advantage of the federal defense research and development investment.

Technology transfer at Sandia takes many forms. We are engaged in a variety of activities, including personnel exchanges, patent licensing, use of facilities, cost-shared contracts, technical assistance, information dissemination, participation in industrial consortia, and cooperative research and development agreements (CRAI)As). It is instructive to distinguish three different technology-transfer pathways: (1) R\&I) Partnerships, (2) Technology Deployment, and (3) Entrepreneurial Initiatives.

\section{R\&D Partnerships}

Since 1991 (the first year that our legislative mandate was codified), the (RAI)A has become our most successful technology transfer mechanism. (RAD)A projects are distributed more or less evenly over five broad technical areas: advanced manufacturing and precision engineering, materials and processes for manufacturing, microelectronics and photonics, high-performance computing and applications, and energy and environment. (Appendix A lists many of the Sandia (RAD)As that D)( L) has approved in these categories as part of the Defense Programs Technology Transfer Initiative.) Since our first (RADA was signed in June 1991, Sandia has initiated approximately 150 CRAI )As with a total value approaching $\$ 500$ million.

Although the number of (RAD)As does reflect the growth of our R\&D ) partnerships, it is not necessarily an effective measure of the success of a technology transfer program. Industry must provide the ultimate evaluation of success or failure. At our one-hundredth CRADA celebration, we resolved to solicit more quantitative feedback from our industrial partners to help measure the contributions of our technology transfer program.

In general, our industry partners have judged the value of their association with us favorably. The feedback we have gathered is forming the basis for meaningful improvements. Despite initial procedural obstacles, we are currently oversubscribed in our (CRAI)A program by a substantial margin and have received many solicitations by industry for non-CRAI)A cooperative work. Most important to us is direct feedbac's from industry that provides "first-person" views of the value that Sandia has added to their companies. A sampling of these comments is provided in Appendix B and includes such key phrases as "dramatic improvement in performance," "annual energy savings of $\$ 100,000$," "your suggestions were a great help to our manufacturing process ... and| reduced the cost."

To help ensure that the broad range of Sandia's talents and facilities is directed effectively toward meeting industry's needs, our new technolngy transfer organizational structure features product-area engineers (people with technical as well as business backgrounds). In the future, product-area engineers, together with technical area coordinating teams composed of specialists from industry, laboratories, and the academic research community, will integrate technology transfer considerations into the planning and conduct of all laboratory research and development.

A Move Toward Larger-Scale Alliances - Our strategy for technology transfer has evolved from maximizing the number of small (CRADAs to seeking large-scale alliances with industry and universities. In the last two years, we have began to focus on teamwork arrangements with clusters of companies and larger-scale alliances in which the capabilities of DOE: laboratories, industry, and universities are combined to pursue broad, industry-driven precompetitive $R \& D$ ) agendas. Many of our newer (CRAI)A projects involve clusters of companies representing a substantial segment of a specific industry, or involve working with organizations that represent an entire industry.

lor example, we are working with a cluster of companies under a (RADA with MacNeal Schwendler Corp., PI)A Engineering, Hluid Dynamics International, and Ford Motor Company to develop mesh-generation computer software to shorten the cycle time for developing production prototypes. This Sandia-led consortium is conducting precompetitive generic research that will benefit an entire industry. Each industry participant will use the software to develop a commercial product or service in the area of computer-aided engineering software or in applications for finite element analysis-- a powerful numerical method useful in many industrial engineering applications, including structural mechanics, electrical engineering, and fluid mechanics.

In an agreement with the Specialty Metals Processing Consortium, Sandia is working with the critically important U.S. specialty metals industry to improve the technology base for melting processes used in manufacturing specialty metals. Specialty metals, such as highperformance steel and titanium or nickel-based alloys, are critical to American economic competitiveness in areas ranging from microelectronics to airplanes and are also vital to national security. The Specialty Metals Processing Consortium has conducted several major investigations. Most of the research has taken place within Sandia's Melting and Solidification Laboratory complex, which features the only large-scale, fully instrumented research furnace in the country. Results of the industryselected research projects are enabling and generic in nature so that each member company can develop its own proprietary processes and products. Patents resulting 
f.rom this work will be made available to consortium members through a royalty-free licensing arrangement.

A five-year CRADA with SEMATECH is aimed at developing improved semiconductor manufacturing technologies for the next generation of integrated circuits, including equipment that reduces manufacturing costs while increasing yield. This CRADA builds on a relationship established with SEMATECH in 1989 when Sandia's Semiconductor Equipment Technology Center was formed. It also extends a 1992 agreement that established the Contamination-Free Manufacturing Research Center at Sandia to study ways to reduce trace levels of contamination in semiconductor manufacturing, a critical problem facing microelectronics manufacturers. This work should help U.S. semiconductor equipment manufacturers compete with foreign suppliers.

Sandia is also a participant in the American Textile Partnership (AMTEX), a research and development collaboration between the Department of Energy, DOE's multiprogram laboratories, universities, and the textile industry. The goal of this recently organized joint effort is to strengthen the competitiveness of the integrated U.S. textile industry by pursuing a broad, industry-driven research agenda. AMTEX institutions are the Institute of Textile Technology, Textile/Clothing Technology Corporation, Textile Research Instituie/Princeton, Cotton Incorporated, and the National Textile Center, a consortium of four leading textile research universities.

Many of these and other examples of collaboration with the private sector (including our CRADA with the United States Advanced Battery Consortium, which was described earlier) exploit unique research facilities at Sandia National Laboratories that are part of the federal Rĩ D infrastructure and can be leveraged for great benefit to industry. These centers and user facilities are vital mechanisms for technology transfer and are generally available to industrial partners to ensure that U.S. industry gets maximum benefit from this technology base. The research and technology development activities conducted at these facilities satisfy a broad spectrum of dual-use needs for government and industry. Appendix $C$ provides a listing and description of the research centers and user facilities available at Sandia for collaborative technology development with industry and universities.

\section{Planned Improvements in Technology Transfer Strategy-} The future holds great promise for more effective mechanisms and strategies for technology transfer, or rather, technology collaboration in a broad sense. We are refining the measurement systems and feedback mechanisms we use to evaluate how well technology collaboration is achieving its goals and how it can be improved. As I mentioned earlier, industry must be the ultimate judge of the effectiveness of such programs, and we will continue to look to industry for their candid evaluation, recommendations, and leadership.
In my view, federal $R \& D$ investments in support of economic competitiveness will yield their full potential only if at least two critical requirements are met:

1. The investments target major national technology goals that are market-driven, industry-defined, and precompetitive.

2 . The investments lead to a high degree of collaboration among industry, universities, and federally supported laboratories, utilizing federal/industrial costsharing arrangements to the fullest extent possible.

Satisfying these requirements becomes more feasible as joint research and development activities become more common and the scope of industrial cooperation expands. Major industry trade associations are developing precompetitive technology strategies or "road maps" that outline technical and business strategies for joint-sector assaults on major industry problems and opportunities.

For example, the Semiconductor Industry Association recently issued a technology plan for the U.S. microelectronics industry through the year 2013. The plan was assembled by 179 top U.S. semiconductor experts from industry, government, and universities. This "road map" identifies opportunities for the DOE multiprogram laboratories to help industry address their generic technology needs.

In response to the Semiconductor Industry Association's directly stated needs, Sandia established its Center for Microelectronics Technologies to assist the industry in dual-use projects. This centei was created by combining the existing, DOE-funded Microelectronics Development Laboratory at Sandia with a major donation of equipment and research instrumentation from IBM valued at over $\$ 20$ million. The center will create a centralized user facility for industry and spawn partnership projects with U.S. microelectronics manufacturers and universities to develop the technologies, manufacturing equipment, and advanced processes upon which the future of both commercial and defense electronics depends. The center will also serve as the arena through which future generations of U.S. graduate students will be trained in the most advanced integrated circuit technologies in the world.

A combined governing board will choose projects that create teams of researchers selected from U.S. universities, industry laboratories, and the DOE multiprogram laboratories with major industry partners who agree to commercialize the results. The federal government is a major beneficiary of this joint work, both through the development of custom products for government applications and through support for the domestic manufacturing base that provides these products.

Similarly, the U.S. Optoelectronics Industry Development Association (OID)A) has created a technology road map to chart a course for joint action to advance industry opportunities in the emerging optoelectronics market. OIDA has selected five critical areas for joint research and development at the precompetitive stage. 
Two of the critical enablers for this research - optoelectronic materials and optoelectronic manufacturing processes and equipment - are areas in which Sandia has recognized technical leadership. 'The laboratories' Compound Semiconductor Science and Technology Center provides an ideal facility at which cost-leveraged partnerships involving U.S. industry, universities, and government researchers can perform the precompetitive development of the design tools, processes, and related production equipment essential for U.S. optoelectronics manufacturers. We are currently exploring proposals for collaboration in research and development work with the optoelectronics industry to implement the technology road map it has defined. As envisioned, an advisory board will recommend projects that combine teams of researchers from both government and industry laboratories and universities. The teams will include major industry partners who will commercialize research results.

These two examples of industry/university/D) laboratory teamwork based on industry-defined road maps are a glimpse into the future of joint-sector collaboration. The benefits accrue to the industry as a whole and the nation's high-technolo: industrial base is strengthened.

\section{Technology Deployment}

Our strategy for the future also includes enhancing the accessibility and flow of technical assistance to small and medium companies. This includes the licensing of DOE-developed technologies to small enterprises that are willing to assume the financial risks of product commercialization.

We have established a Small-Business Technology Transfer Program in conjunction with Lawrence Livermore and Los Alamos national laboratories and the $\mathrm{Y}-12$ production facility at Oak Ridge. This program is a follow-on to the successful National Small-Business Technology Exchange Program. The mission of the Small-Business Technology Transfer Program is to make the DOE, multiprogram laboratories' resources available to small and medium-sized businesses. We work with small-business development centers, cooperative extension services, bankers, chambers of commerce, state economic development agencies, and vocational education teachers to identify technology partners. Included in the program are regional, short-term technical assistance programs in New Mexico, California, Arizona, Texas, and the Midwest. Also included are partnerships with industry associations to reach a greater number of small business participants by addressing common problems and oppcrtunities and matching laboratory capabilities with the needs of small businesses.

We are creating new programs to make the environmentally conscious manufacturing technologies developed at Sandia available to small and medium businesses. An example is a proposed joint DOE:LPA/ Commerce Environmental lixtension Enabling Program in which Sandia will work with extension entities of the
National Institute of Standards and Technology (NIST) to identify small business needs. We will help develop and commercialize technologies and facilitate technology deployment by training and providing advisors for NIST, state extension agents, and small businesses. We will focus on developing an on-line knowledge base for environmentally conscious manufacturing information, an clectronic "information-on-demand" network via a teaching factory at Sandia with tools for retraining practicing engineers. We hope to increase the effectiveness of information dissemination through an extensive outreach program that will include a speakers bureau, videotapes, joint activities with industry trade groups, workshops and exhibitions, and a widely distributed Envirommentally Conscious Manufacturing Newsketter.

A new tool for technology transfer, the Technology Information Environment for Industry (TIE-In), is being developed at Sandia. The two primary goals of TIE-In are to increase the leverage of I epartment of Energy technology transfer efforts with a system that can reach hundreds or thousands of small and medium sized businesses and to reduce the investment required by industry to utilize national laboratory technologies.

IIE-In will be supported by a user facility that operates as an electronic extension service to allow users to obtain solutions to problems from remote locations. These users would not require a high level of specialized technical expertise, nor would they incur the very large expenses associated with employing specialized analysts, maintaining software libraries and a software maintenance staff, developing custom databases, and purchasing and operating high-performance computing and experimental equipment.

\section{Entrepreneurial Initiatives}

The effectiveness of Sandia's technology transfer efforts will soon be enhanced even further under a program introduced by its new managing contractor, Martin Marietta Corporation. Technology Venture Corporation, founded by Martin Marietta Corporation, was incorporated in September 1993 for the purpose of fostering the commercialization of laboratory and university technologies through private entrepreneurial activity. It is not a venture capital fund, but is intended to attract private investment dollars and entrepreneurs willing to assume the risk and responsibilities of commercializing technologies developed with tax dollars. In consideration of that risk, appropriate protection will be provided under technology licensing arrangements. This approach has been successfully employed by ()ak Ridge National laboratory, which is also managed by Martin Marietta Corporation, and has resulted in the formation of several start-up companies and many new manufacturing jobs. We have every reason to expect similar success from the Technology Venture Corporation program at Sandia. 


\section{Current Department of Energy Planning Efforts}

Secretary ('l eary has made a strong commitment to the strategic planning process. The Department is taking bold steps to reshape the way it does business in order to meet the challenges of the future. The core values and mission it recently articulated put the customer first and emphasize the importance of people as the ultimate creative resource for solving national problems. DOE:'s customer is, of course, the taxpaying public as represented by its elected officials. This has always been true, but in the past this fact was perhaps not internalized as a motivational focus.

I believe the I)epartment of Energy is undergoing fundamental change. If it succeeds with this change process - a redefinition of how it does business - the Department will become a strong force for meeting the science and technology needs of the nation in the next century. It is our intention, as a major DOE multiprogram laboratory, to help DOE succeed in this process, as it must for the good of the nation.

One of the useful things to come out of the DOE strategic planning process is a recognition of the critical factors for success in its missions and as an agency. Those factors include the effective use of human resources; the efficient deployment of business systems; understanding DOE's lines of business and priorities; making, environment, safety, and health a priority in all IOOF activities; fostering understanding and trust in its dealings with its customers and with other members of the DOE community; and using science and technology effectively in its programs to ensure success.

The DOE planning architecture is organized in three management improvement initiatives: strategic planning, human behavior, and total quality management. These efforts are typical of change initiatives commonly undertaken in the private sector to improve corporate performance. It is clear that they have the support and authority of the Secretary herself, and I am confident that they will result in real changes that make the Department and the laboratories more effective.

Some important outcomes are already emerging from these planning efforts. Foremost is a clear articulation of I)E's enduring core mission responsibilities (or "business priorities" in the terminology of strategic planning) in energy, environment, nuclear weapons, and the scientific and technological foundations upon which DOE mission success ultimately rests. As a corollary, the relevance of DOE'S mission responsibilities and science and technology capabilities to the challenge of industrial competitiveness is explicitly acknowledged.

I am also encouraged that the importance of interagency cooperation and collaboration is more widely acknowledged within the DOE, especially with such agencies as Commerce, Defense, the National Aeronautics and Space Administration, and the Envirommental Protection Agency, all of which are organizations with major science and technology responsibilities. I also believe the Department of Energy appreciates the critical role that its multiprogram national laboratories must continue to play in supporting its evolving missions.

\section{Conclusion}

The Department of Energy and its multiprogram laboratories have made a good start in aligning their efforts with new national priorities. There is much to be accomplished and much opportunity for all of our nation's technical institutions to contribute. The collaborative efforts we have begun should be encouraged and improved. Let us not discourage the cooperative and entrepreneurial spirit that holds such promise for leveraging national science and technology resources for multiple benefits. 


\section{A Sampling of Sandia Cooperative Research and Development Agreements Sponsored by the DOE Defense Programs Technology Transfer Initiative}

\section{Technology Transfer Initiative Participants in High-Performance Computing and Applications \\ Technology}

Company

Amoco Oil Company

AT\&T

BIOSYM Technologies

BIOSYM Technologies

Fluid Dynamics International

Ford Motor Company'

MacNeal-Schwendler Corp.

PDA Engineering

Photonics Imaging
Simulation of residual oil hydroprocess units Experimental high-speed network test bed Mathematical libraries for modeling materials Molecular design of polymer alloys Sandia mesh-generation computer software Sandia mesh-generation computer software Sandia mesh-generation computer software Sandia mesh-generation computer software Plasma flat-panel video monitors

\section{Technology Transfer Initiative Participants in Materials and Processes for Manufacturing}

\section{Company}

Aluminum Company of America

Amoco Chemical Co.

AT\&'T

Carpenter Technology

Dow Corning Corp.

Dupont

GE Superabrasives

General Motors

General Motors

General Motors

General Motors

GeoCenters

National Center for

Manufacturing Sciences

National Center for

Manufacturing Sciences

Norton Co.

Permacharge

TN Technologies

Xsirius Inc.
Technology

Processing of aluminum alloys

Polymeric non-linear optical meters and devices

Gold-sulfite electroplating

Joining technology for borated stainless steel

Micro-engineered materials

Diamond reinforced composites

Synthetic diamond substrates

High-temperature electronics

Intelligent systems for induction hardening processes

Light-weight material for automotive applications

Thermal spray technology for cylinder bore coatings

Intelligent sensors for composite materials manufacturing

Prediction models for distortion

Wiring board interconnect systems

Large area polycrystalline diamond substrates

Microcellular foam filtration media

Mercuric iodide sensor technology

Mercuric iodide sensor technology 


\section{Technology Transfer Initiative Participants in Energy and Environment}

Company

General Motors

General Motors

RIMtech
Technology

Reduction of nitrogen oxide emissions

Engine fluid condition monitors

Borehole radar imaging technology

\section{Technology Transfer Initiative Participants in Microelectronics and Photonics}

\section{Company}

Advanced Micro Devices

Alpha Industries

Analog Devices

AT\&T

Charles Evans \& Associates

Conductus

Hewlett Packard

Hewlett Packard

Hewlett Packard

Hewlett Packard

J. W. Harley

LAM Research Corp.

LS! Logic

Microelectronics \& Computer Technology

National Semiconductor

Radiant Technologies

Radiant Technologies

Schlumberger Technologies

Schumacher Inc.

SEMATECH

SEMATECH

SEMATECH

Signetics

Texas Instruments

Texas Instruments

Thunder Scientific

University of New Mexico

Watkins-Johnson
Technology

New integrated circuit manufacturing technologies Manufacturing of monolithic microwave memories Microelectronics quality reliability center

Projection $x$-ray lithography using a laser plasma source Advanced detector for light element profiling

Confocal resonator imaging systems for surface assembly Advanced manufacturing techniques for optoelectronics Field emission source with phosphor screen Properties of visible light-emitting diodes Wafer-level accelerated reliability testing software Fiber optic hydrogen sensing Advanced intermetal dielectric technology Development of failure analysis for integrated circuits Field-emission flat-panel display

Characterization of silicon gate oxides Ferroelectric read/write optical disc Nondestructive readout nonvolatile memories Failure analysis system for integrated circuits Chemical vapor deposition of copper Benchmarking microelectronics and manufacturing equipment

Contamination-free semiconductor manufacturing

Semiconductor equipment reliability, modeling, and design

Characterization of failure analysis for integrated circuits Chemical vapor deposition of copper

Semiconductor plasma processing Fabrication of porous silicon humidity sensors Fabrication of microreactors in silicon Chemical vapor deposition of copper 


\section{Technology Transfer Initiative Participants in Advanced Manufacturing and Precision Engineering}

\section{Company}

Amax Plating, Inc.

AT\&T

City of Albuquerque

Cray Research

Digital Instruments

General Motors

General Motors

Kaehr Plating \& Metal Finishing

Pratt \& Whitney

Pratt \& Whitney

Precision Fabrics Group, Inc.

Rocketdyne

University of New Mexico
Technology

Electroplating process control

Noncontact atomic level interface force microscope

Volatile organic monitor for industrial effluents

Environmentally safe manufacturing of printed wiring boards

Noncontact atomic level interface force microscope

Knowledge-based system for materials selection

Simulation \& analysis of robotic assembly devices and fixtures

Electroplating process control

Automated surface and edge finishing

Intelligent processing of thin-section welded assemblies

Lightweight safety restraint

Intelligent processes for welding, machining, and assembly

Noncontact atomic level interface microscope 


\section{Appendix B}

\section{Highlights from Customer Responses on Sandia's Technology Assistance Performance}

"I would like to express my appreciation for the interaction of Sandia National Laboratories' Combustion Research Facility ... . Due in large part to Sandia's input, we are continuing to make progress in solving combustion-related problems. The primary improvements are in Improved Efficiency and Reduced Waste (which) . . could total approximately $\$ 1,000,000$ annually."

- L. E. Nemcek, Northern Indiana Public Service Company, Gary, Ind.

"I am sending this letter to express my deep gratitude for the assistance you rendered for our company. ... As of the end of April, we completely eliminated the use of Freon in our facility. As you suggested we are using solvent terpene, followed with a plasma clean. Your suggestions were a great help to our manufacturing process ... [and] reduced the cost of solvent to $\$ 12$ per gallon [from \$62 per gallon]."

- Yuni Corcoran, RSM Electron Power, Inc., Deer Park, N.Y.

"We would like to bring to your attention an example of an outstanding technology transfer effort conducted by the Sandia National Laboratories. As a result of implementing Sandia's recommendations, we have witnessed a dramatic improvernent in the performance of the solar [energy/ system, along with significant electrical energy cost savings. For the year 1991, equipment availability increased from 53\% to 82\% and our net electrical energy cost savings exceeded $\$ 60,000$. The complete refurbishment will cover a two-year period, or until the system is $100 \%$ operational. At that time, we expect net annual energy savings of \$100,000."

-D. C. Knipfer, D. L. Simmons, and R. H. Combs, Gould, Inc., Chandler, Ariz.

"I am writing this letter to formally acknowledge the great strides we have made here at Ford in mesh technology due to our involvement with the Sandia Mesh Consortium. ... We are currently in the process of putting the new Sandia/ACIS based paving software into production as one of our fundamental element tools. A recent benchmark of the software showed a reduction in modeling time from 36 hours to $1 / 2$ of an hour. Our users consider this substantial."
"We could not have developed this quality testing instrumentation [Sandia Wafer-level Software for Reliable DevicesSWORD] alone. [Sandia's Electronics Quality/Reliability Center physicists and engineers are painstakingly careful in whatever they do. I have never worked with a gr sup of people who put so much effort into a project. They were eager to make a success out of this product. ... The reason [customers] buy our package is because of Sandia's reputation in reliability testing. We are finding in the United States and worldwide everyone wants SWORD, because we developed it with Sandia National Laboratories."

\section{— Greg Miller, Hewlett-Packard}

"I am writing on behalf of nCUBE to express our appreciation for the numerous benefits Sandia National Laboratories has brought to nCUBE over the years as a development partner .... While Sandia created and explored new frontiers in massively parallel computing, Sandia scientists provide valuable insight and feedback to $n C U B E$, especially in the critical area of software development. Sandia, for example, helped to develop the logarithmic load and dynamic load balancing programs that dramatically reduced application broadcast load on massively parallel supercomputers. . . Finally, as we look to the future, nCUBE hopes to benefit from Sandia's valuable input and feedback."

- Len Eschweller, nCUBE

- M. Paul Shank, Ford Motor Co. 


\section{Appendix C}

\section{Sandia National Laboratories Dual-Use Research Centers and User Facilities}

\begin{abstract}
Aging Aircraft Nondestructive Inspection and Validation Center-The mission of this center is to encourage the development of nondestructive inspection techniques applicable to aircraft structural inspection, to validate this technology through assessing its reliability and costeffectiveness, and to interface the inspection portion of the Federal Aviation Agency's National Aging Aircraft Program to the civil aviation industry.
\end{abstract}

\section{Center for Contamination-Free Manufacturing - This} center was formalized by a cooperative research and development agreement between SEMATECH and Sandia in 1992. The center exploits the unique layout of Sandia's Microelectronics Development Laboratory to conduct experiments to verify advanced semiconductor manufacturing concepts and equipment which can reduce contamination that limits the yield of integrated-circuit manufacturing processes.

\section{Center for Liquid-Metal Processing Technology - This} center uses industrial-scale processing equipment under research or development to improve liquid-metal processing techniques and associated control methodologies. Current industrial collaborations include work on vacuum arc remelting, electroslag remelting, electron beam melting, investment casting, and thermal spray processing (plasma spray, flame spray, wire arc spray). Interdisciplinary research is in progress to define process physics, advance equipment technology, provide industrial process monitoring capabilities, develop robust multi-variant control methodologies, and establish agile manufacturing capabilities, including rapid prototyping.

Center for Microelectronics Technologies - The capabilities offered by this center are accessed by industry through a five-year, $\$ 100$ million cooperative research and development agreement with SEMATECH, as well as through CRADAs with individual companies. Center activities in support of the U.S. semiconductor industry include the Semiconductor Equipment Technology Center (SETEC) and the Contamination-Free Manufacturing (CFM) Research Center. The Center for Microelectronics Technologies conducts projection $\mathrm{x}$-ray lithography and projection electron-beam lithography programs jointly with industrial partners to develop the next generations of processes and processing equipment. The center is the site for developing environmentally conscious procedures for semiconductor manufacturing.

Center for Solder Science and Technology - This center addresses a mixture of old and new soldering problems that hinder the rapid evolution of microelectronic technologies. Environmentally compatible replacements in ozone-depleting chemicals are being developed in anticipation of new EPA regulations. The center is also developing a variety of fluxless soldering techniques that can eliminate solvents and hazardous wastes generated during electronic soldering. It is currently developing lead-free solders and solder pastes as alternatives to lead-containing solders used throughout the electronics industry.

Combustion Research Facility - The Combustion Research Facility, opened in 1980 at Sandia's California site, provides an excellent example of the Laboratories' commitment to partnerships with industry and universities. The facility is a designated DOE user facility chartered to conduct a broad range of fundamental and applied research and development in combustion science and technology. Research is conducted in collaboration with visiting scientists and engineers from industry, academia, and federal laboratories. Advanced experimental techniques, emphasizing laser-based diagnostics and advanced computational models, are used in the combustion science and technology programs. Novel sensors and computational models from the programs are in active use in major U.S. industries.

\section{Compound Semiconductor Research Laboratory -} This facility encompasses the full range of activities required to develop the next generation of compound semiconductor electronic and optoelectronic devices. Facilities include extensive molecular beam epitaxy and metal-organic chemical vapor deposition crystal growth capabilities, ion implantation, and e-beam lithography in a 6,000-square-foot, Class-100 clean room with stateof-the-art processing equipment.

Environmentally Conscious Process Center - This center addresses the development of cost-effective processes for reducing wastes and improving energy utilization efficiency in manufacturing processes. It promotes the idea that designers, process engineers, and materials engineers must be included in a cradle-to-grave, totally integrated systems approach to all phases of advanced manufacturing. Center activity is focused on life cycle analysis; solvent and chemical substitutes; soldering (including lead-free solders); cleaning technologies; electroplating and surface finishing; sensors for environmental monitoring, reliability and cost/benefit/risk analysis; alternative polymers and foams; vendor compliance; small-business 
outreach; and dismantlement, recycling, and reuse. Industrial sectors of particular interest include automotive, electronics, chemical, and textiles.

\section{Integrated Manufacturing Technologies Laboratories -} This collection of laboratories comprises an interdisciplinary mix of equipment and personnel focused on the development and integration of technologies for advanced manufacturing. Created in 1992 at Sandia/ California, the facility will be fully functional in 1994 . Activities include materials and process research and development, process simulation, engineering design, and manufacturing technology support. During the start-up phase, the focus has been on projection $\mathrm{x}$-ray lithography, welding, precision machining, metrology, and composites fabrication. These activities will be supported by high-speed, fiber optic communications and on-line monitoring and control systems. Flagship programs include SMARTWELD, an integration of modeling, simulation, and sensors with actual welding processes to allow fabrication of critical components without extensive development time and costs; and soft x-ray projection lithography (SXPL), where a laboratory-based machine will be scaled-up to demonstrate integrated circuit fabrication at sub-micron line widths.

Intelligent Systems and Robotics Center-This facility is a fully integrated research-to-development-to-application center that provides technologies for intelligent and agile manufacturing. Specific areas include design for manufacturing and assembly, work environment design, systems engineering and integration, process modeling and simulation, precision machining, joining, assembly, automated inspection, integration frameworks, software engineering, artificial intelligence, expert systems, robotics, machine/cell/process control, and sensors/sensor fusion. The center is the focal point for Sandia's work in information-driven manufacturing and has more than 40 laboratories available for collaborative research and development.

Microelectronics Development Laboratory - The 74,000square-foot Microelectronics Development Laboratory (MDL) includes 30,000 square feet of clean-room space with 12,500 square feet of Class 1 clean space in 22 separate clean rooms. The laboratory's design provides maximum flexibility for new processing equipment and device technologies and is uniquely configurable to support the joint Center for Contamination-Free Manufacturing. A major donation of equipment and technology by IBM provided a state-of-the-art, sub-micrometer, silicon integrated-circuit research and development line. The laboratory's complete equipment set supports the total semiconductor development cycle, including research, design, fabrication, test, prototype delivery, qualification, and technology transfer. Four bays of the MDL are planned to be dedicated to activities of the
Multi-Chip Module Foundry Consortium and will be used as an equipment applications laboratory. This unit will be an industry-shared site with all next-generation manufacturing equipment and will offer manufacturers, material suppliers, and equipment vendors an efficient way to perfect equipment, materials, and processes.

National Center for Advanced Information Components Manufacturing - Beginning in 1993, the Advanced Research Projects Agency is sponsoring the National Center for Advanced Information Components Manufacturing at Sandia to provide a resource for integrating federal and commercial research and development of advanced information components. This integration will provide the capability for the United States to greatly compress the time to translate research and development into commercial and defense products. Los Alamos and Lawrence Livermore national laboratories will also support the center, along with representatives from industries and universities. The center will allow industry and government researchers to exploit a range of competencies in microelectronics and photonics, electronics systems packaging, materials science and processes, printed-circuit fabrication, and other product development tools. Research will concentrate on agile manufacturing technologies associated with advanced silicon integrated circuits, high-speed optoelectronic communications, and electronic systems and subsystems. Research in large, flat-panel displays will benefit from the consolidation of supporting technologies at a single site. Manufacturing research will focus on developing agile manufacturing processes for flat-panel products for both defense and industry.

\section{National Center for Advanced Manufacturing Technology} - This center was established at Sandia in 1991 to maximize the value of the Laboratories' technology base to the manufacturing needs of both the DOE nuclear weapons complex and industry. The center will help transfer and apply advanced manufacturing technologies developed in Sandia's defense programs to commercial manufacturing, thus helping to strengthen U.S. industry's competitiveness. The center serves as a gateway by which private industry, academia, and government agencies can gain access to the technical capabilities provided at Sandia.

National Center for Ultra-Reliability Engineering (NCURE) - This center seeks a U.S. competitive advantage in high-value products and systems through leadership in the technology that makes it possible to achieve high quality. Activities include research and development on how devices fail, advanced approaches to reliability assurance, and multidisciplinary test and evaluation capabilities. The center will support a reliability "SWAT team." A particular emphasis of NCURE is assuring high reliability in small-lot agile manufacturing. The NCURE program has a dedicated staff of three people with 
approximately 100 people working on various aspects of reliability technology.

National Solar Thermal Test Facility - This facility was constructed in 1977 as a designated DOE user facility. It is used by industry and government for tests requiring intense heat and for collecting light with large-scale optics. Specific high-thermal flux applications include investigating the thermophysical properties of materials and testing various solar applications. Large-scale optics can be used for astronomical observations and atmospheric sounding with lidar. Testing is done in support of several joint venture agreements involving DOE, Sandia, and industry, as well as reimbursable programs for customers such as the U.S. Navy, Air Force, and Defense Nuclear Agency. Test areas include a field of 222 computer-controlled heliostats that reflect concentrated solar energy onto a tower 61 meters ( 200 feet) high, two 10.8-meter (36foot) diameter parabolic dishes, two solar furnaces, and a series of line-focus parabolic troughs that track the sun in one axis to concentrate solar power in a line.

Process Development Laboratory - This laboratory is a center for advanced prototype manufacturing housed in a 100,000-square foot facility at Sandia/New Mexico featuring hybrid microcircuits, thin films, printed circuits, ceramics, plastics, and rapid prototyping capabilities. The laboratory coordinates its activities with the Integrated Manufacturing Technologies Laboratory at Sandia's California site. The charter of the laboratory is to focus on reliability and quality of manufacturing processes through understanding and qualification of manufacturing processes. This facility also acts as a proving ground for custom sensors for manufacturing processes.

Semiconductor Equipment Technology Center (SETEC) - SETEC was established in mid-1989 to support SEMATECH in improving the competitive position of the U.S. semiconductor industry. The program has three goals: (1) improving equipment reliability, (2) developing diagnostic techniques for monitoring processes and adapting these techniques to improved process control, and (3) developing models for describing and optimizing manufacturing equipment design and processes. SETEC operations are supported by a staff of approximately 35 people and a cooperative research and development agreement with SEMATECH. SETEC is yielding significant improvements in a number of areas critical to ensuring that the U.S. microelectronics industry will have the reliable, high-quality equipment it needs to remain competitive in global markets. The center's operations are expected to expand into other areas including semiconductor equipment design, semiconductor equipment characterization and improvement, and semiconductor manufacturing control and diagnostic sensor technologies. 


\section{A Sampler of Sandia National Laboratories Technology Transfer Achievements}

Researchers at Sandia and the University of New Mexico School of Medicine have patented a sensor that measures blood glucose without drawing a blood sample. By providing an accurate, painless method for measuring serum glucose, this technology, which grew out of experiences gained in the weapon program, could greatly improve the quality of life for people with diabetes and reduce the incidence of complications from the disease. Indeed, a recent study by the National Institute of Diabetes and Digestive and Kidney Diseases showed that a program of controlling blood sugar to near normal levels through frequent monitoring can dramatically reduce the risk of developing eye disease and kidney disease and incurring nerve damage.

The sensor employs infrared spectroscopy and statistical techniques for processing spectral data. Nearinfrared light is used, which has a slightly longer wavelength than visible light and can penetrate skin. When the light is transmitted through a finger inserted in the monitor, a portion of the light at each of various wavelengths is absorbed by the components in the tissue and blood, including glucose. After passing through the finger, the light is dispersed into a spectrum and the spectral data are analyzed for glucose-specific absorptions to determine glucose concentrations.

In the 1970s, Sandia developed and transferred to industry a miniaturized implantable insulin pump. The pump was tested in about 700 patients worldwide. If the glucose sensor - which may permit continuous monitoring, not just point-in-time measurementswere combined with an insulin pump, an artificial pancreas could possibly be developed.

Sandia and Hewlett-Packard have developed improved process monitoring, active control, and feedback systems for the fabrication of advanced optoelectronic devices. Improved epitaxial materials and processes yield higher reliability compound semiconductors, transistors, and optoelectronic devices for commercial and defense applications. This laboratory/industry partnership helps maintain state-of-the-art device fabrication capabilities in a period of reduced weapon manufacturing. Through this partnership, the critical device prototyping capabilities of Sandia are maintained and enhanced.

Sandia and SCB Inc., a small New Mexico business, have developed a very safe and economical semiconductor bridge initiator for civilian and military explosives applications. These devices have enhanced electrostatic discharge and no-fire safety and operate at much lower energies than is possible with contemporary hot-wire technology. 'The device will eliminate the need for weapon components made with known or suspected carcinogenic compounds. It could also be incorporated in automobile airbags for application in multi-bag systems with stringent safety requirements that cannot be satisfied with currently available technology.

LSI Logic, one of DOE's largest suppliers of integrated circuits and a leading supplier to the commercial electronics market, is using an induced voltage alteration technique developed at Sandia to locate failure sites in defective integrated circuits as they are fabricated. This technique is capable of locating failures in an hour or less, a considerable improvement over the two weeks normally required when using an electron microscope. As a result, LSI has improved the efficiency of its fabrication and has eliminated a six-month backlog in its failure analysis. In a related effort, Signetics and Sandia jointly developed an advanced wafer level reliability microelectronics and therefore a need to identify, characterize, and control the same failure mechanisms. Improvements such as these helped the U.S. microelectronics industry surpass foreign competition for the first time in a decade.

Sandia and BIOSYM Technologies, Inc. worked together to develop computer software that helps design polymer alloys. Polymer alloys are leading candidates to meet the evolving need for high-strength, lightweight, inexpensive, environmentally acceptable materials. This new software, called PRISM, has been licensed by BIOSYM to a recently formed consortium of polymer manufacturers. The molecular modeling capabilities resulting from this project should be of great utility to the U.S. polymer industry since polymer alloying is less expensive and more versatile than synthesizing and developing entirely new polymers. The information gained from this program will aid the development of high-performance polymer blends and copolymers for various weapon applications. New materials that could result include high-strength encapsulants for packaging electronic subsystems in nuclear weapons, lightweight structural supports for nuclear weapons, and new optical materials for nuclear safety.

Sandia and Martek Lasers, Inc., developed a high-powered continuous-wave laser welding system. The company was recently purchased by Hobart Brothers Company, one of the top U.S. manufacturers of welding equipment. This state-of-the-art system helps the U.S. retain its position in the high-technology laser welding market. 
These laser welding systems are now fully commercialized and used by organizations that include the U.S. Navy and the major automobile manufacturers. Weapon systems use a diverse range of inaterials in challenging geometries, and precision welding and joining are critical processes. Improved laser weiding technology helps the weapons program fulfill these demanding requirements.

Sandia and SEMATECH have been working together since 1989 on several programs to enhance the performance of precision microelectronics fabrication equipment, improve and assure the quality of microelectronics components, and explore advanced chemical processes for producing complex integrated circuits in an environmentally responsible way. A reliability training program, derived from quality assurance techniques developed for nuclear weapons, has been developed for the SEMATECH member companies. Sandia has also modified weapon design and analysis technologies to improve integrated circuit fabrication processes.

Through this partnership, DOE Defense Programs and the microelectronics industry both obtain improved microelectronic fabrication processes that enhance U.S. competitiveness and national security. The partnership has proved so successful that SEMATECH and Sandia have announced another five-year, $\$ 100$ million partnership to jointly develop equipment to produce the next generation of computer chips.

Sandia is working with J. W. Harley, a small business in Ohio, to commercialize a fiber optic hydrogen sensor, originally developed at Sandia, to monitor nuclear facilities. The sensor provides a warning when hydrogen gas builds up inside electrical transformers. Use of the sensor in large power transformers can prevent explosions. Transformer explosions can result in millions of dollars in financial loss and even loss of life. This hydrogen sensor has global commercial market potential. DOE Defense Programs will have a reliable, affordable commercial source for sensors to improve worker safety in nuclear facilities. Similar sensors hold promise for other applications, such as monitoring the cleanup of weapons facilities. 


\section{Appendix E}

\section{Sandia National Laboratories Major Accomplishments of 1993}

Sandia expanded its massiveiv-parallel supercomputer, the Intel Paragon, to 1,827 nodes. In September we achieved a computational speed of greater than 100 gigaflops ( $10^{11}$ floating point operations per second) - a world record. Funding for the computer came from Department of Energy, the National Science Foundation, and the Advanced Research Projects Agency of DoD. It is an important tool in the work of the National Consortium of High Performance Computing.

Sandia demonstrated the world's fastest computer information network across the 1,100 miles between Sandia's California and New Mexico sites. This linix was used to consolidate all of the Cray supercomputers at the New Mexico site while providing distributed computing to California users in a completely transparent manner. This step is a major advance in demonstrating technologies that will be needed to create the National Information Infrastructure.

Sandia has developed a new sensor to determine the condition of lubricating fluids in internal combustion engines. Based on a rugged quartz resonator device, the unit has successfully monitored engine oil to determine the end of useful life. This solves a major dilemma for automobiles, trucks, and tractors : determining when to change oil. The device successfully measured density, viscosity, precipitation rate, and contaminant concentration. Two industrial partners, General Motors and Dickey-John, are developing products based on this result.

Sandia's automatic mesh generation software, which won an R\&D 100 Award and the Federal Technology Transfer Award in 1993, has been successfully transferred for industrial engineering design applications. Ford Motor Company reports that, based on this technology, it has been able to reduce major engineering design iterations from 36 hours to less than 12 hour. Goodyear Tire and Rubber is now bringing the software on-line for tire designs.

Sandia obtained DOE approval to enter into 64 cooperative research and development agreements (CRADAs) in 1993 with a total value of $\$ 309$ million. This brings Sandia's total CRADAs to 140 with a total value of $\$ 500$ million. A majority of the CRADAs are in advanced manufacturing and electronics technologies.

Sandia has demonstraied an advanced $x$-ray lithography system to produce microelectronic chips with line widths of less than one-tenth micron. The system used all reflective optics, 134-angstrom radiation, and a precision positioner that utilizes magnetic levitation technology.

Sandia demonstrated a computer-networked system that unites design, analysis, and fabrication tools for on-line welding applications. Called SMARTWELD, the system is already reducing scrap rates by analyzing and correcting welding problems in manufactured systems. The new technology was developed for weapons components and is being converted for use by industrial partners for commercial products.

Sandia successfully completed a feasibility study for using supercritical water oxidation to dispose of wastes from obsolete munitions (pyrotechnics, smokes, etc.). Greater than $99 \%$ of such wastes were destroyed in ten seconds within a bench-scale reactor. Conceptual design of a pilo: plant for this technology was completed.

Sandia's new software that allows concurrent engineering to be carried out at distant sites though interactive manipulation of computer drawings and designs has been licensed to Sun Microsystems. They have incorporated it into a larger desktop conference software called ShowMe.

Sandia successfully applied its pattern-recognition algorithms to enhance the analysis of mammograms. In clinical tests carried out at the Scott-White Clinic in Texas in 1993, the enhanced screening process detected malignant tumors with a $14 \%$ higher sensitivity with no increase in false detections.

Sandia demonstrated a system to aid the dismantlement of nuclear weapons by determining the precise location of interior hazardous materials and removing them through precision cutting. The location is determined by real-time radiography and cutting is accomplished by an abrasive water jet. Hazardous materials can typically be removed in less than two minutes.

Sandia developed a solid-state microelectronic sensor for hydrogen. The chip detects hydrogen in wide concentrations within seconds. It was proof tested at NASA's Stennis Space Center and can be applied for nuclear reactor safety, transformer safety, semiconductor processing, and waste site remediation. It won an R\&D 100 Award in 1993 (one of five such awards to Sandia).

Sandia's novel system for achieving a soft landing by deploying airbag technology was successfully demon- 
strated through a variety of tests and analyses. The concept was chosen by NASA for the Pathfinder mission to Mars in 1996.

Sandia demonstrated the operation of a fundamentally new microactuator, the MicroSteam Engine. Fabricated in silicon, the device delivers a force 100 times that of electrostatic actuators. The piston is 2 micrometers by 6 micrometers. Originally developed for weapon surety applications, the device can be applied for micro manipulation of tools and surgical instruments.

Sandia developed a sensor to detect and measure the velocity of groundwater. Groundwater flow is the most important mechanism for dispersal of many toxic wastes, so the new sensor is providing critical information to characterize waste sites and to monitor remediation activities. We have already concluded a license to commercialize the technology.

Sandia, in partnership with three industrial firms, demonstrated a commercial version of a 7.5-kilowatt dish-Stirling solar power system to provide electricity in remote areas. The technology, originally pioneered by Sandia, also won an R\&D 100 award.

Sandia's direct optical initiation system demonstrated full functionality as an advanced nuclear fireset system. It exceeded all goals for delivering optical energy through fibers. Results were significant enough to allow the technology to move to center stage for medical applications of laser light for debridement of wounds, skin treatment, and other laser surgical uses. Two (RADAs were signed with medical centers to transfer the technology.

Sandia's STARS rocket launch system successfully, demonstrated for the first time the marriage of an inertial guidance system with Global Positioning Satellite tracking. This proved to be a highly accurate navigation means from launch to splashdown. The technology offers great potential for precision strike systems of the future. 


\section{Appendix F}

\section{Questions and Answers}

INote: The Housc' Committec on Energy and Commerce/ Subcommitted on Energy and l'ower reguested that the following questions be answered in testimony.)

Question 1: In the post-Cold War world, what objective or quantitative measurements can Congress use to gange the usefiulness and cost-effectiveness of the labs' efforts in different areas ranging from basic research to commercialization?

Response: If usefulness is to be measured in terms of economic benefit, then quantitative metrics are easier to devise for commercialization activities than for basic research.

For commercialization it is possible to measure such things as numbers of patents, licenses, cooperative research and development agreements (CRAl)As), and so forth. However, these measures may not actually be good indicators of the usefulness of a laboratory's commercialization activities. They could actually be deceptive. ior example, a laboratory could have a large number of CRADAs that individually and collectively have a rather small impact. Fewer but larger lab/industry alliances, targeted to major national technology goals and wellcoordinated with key industrial groups might have greater impact.

The best judge of the effectiveness of the laboratories' technology transfer and commercialization programs will always be industry. Consequently, we have turned to industry to advise us and evaluate our efforts. An Industrial Advisory Board, made up of several of the nation's captains of industry, advises the DOE Defense Programs laboratories' offices of Research and Technology Assessment and meets from time to time with the laboratory directors. Recently, the Board recommended three criteria for measuring the success of laboratory/ industry partnerships:

1. How many new products and processes have been incorporated into a company's lines of business?

2. How many improved products and processes have been incorporated into a company's lines of business?

3. How many (RADAs have resulted in showing that an idea was not viable for commercialization?

(This is a successful outcome.)

The Industrial Advisory Board has asked the laboratories to test these criteria against actual (.RAD)As. The results of that exercise will soon show whether or not these criteria are useful metrics.

A key measure for us at Sandia is based squarely on the Total Quality Management principle of customer satisfaction: We ask our (RADA partners to evaluate their experience with the collaboration. In particular, we want to kisow if they would be inclined to commit money again to a partnership with a national laboratory. So far, our responses have been overwhelmingly positive.

Estimating the macroeconomic impact of the national laboratories' commercialization activities is notoriously difficult. In 1986, the Congress's Office of Technology Assessment completed a study entitled Research lunding as an Investment: Can We Measure the Returns? The report concluded that the usefulness of quantitative economic methodologies was limited because technology is only one contributor to the complex phenomena of macroeconomic performance.

However, we expect that quantitative microeconomic measures can be obtained from selected industry case studies. At Sandia, we are in the process of engaging a national economic consulting firm to evaluate our technology transfer activities with a view to providing useful quantitative metrics. Information such as this, together with the consensus of qualitative measures, will help us and 1)( ) develop a more strategic alignment of our industry interactions.

Gauging the economic benefit of basic research is much more problematic. It is a problem that industry has wrestled with for a long time. The pre-divest, ure Bell Telephone laboratories (B'Tl.) provide perhaps the best model for basic research in a national laboratory context. As I mentioned in my written statement, B'TL was vertically integrated. This means that basic research at BTL. was aligned with the company's core business. In this environment, the wall of separation between basic research and applied research and development was crossed easily, and the results of basic research readily flowed into the product development cycle.

The problem of how to quantitatively measure the taxpayers' net return on investment in the national laboratories is not easy. I do not claim to have a complete answer. However, I firmly believe that the Malcolm Baldrige guidelines, the criteria upon which the National Quality Award is based, provide an objective framework for addressing that problem. In accordance with the Baldrige principles, Sandia has adopted Total Quality Management (TQM) as a way to increase its focus on customers and make continuous improvements in laboratory operations. Similar initiatives are being pursued at the other DOE laboratories.

I would be remiss not to mention the importance of metrics and other performance indicators to the $D() E$ laboratories. In accordance with Total (Quality Management 
principles, we are beginning to develop, in conjunction with DOE and our other customers, a more useful system of metrics for laboratory performance. likewise, we are in the midst of an aggressive benchmarking program. It is Sandia's goal to use benchmarking methodologies to characterize all of its programs and to define metrics to assess its performance. Metrics and performance indicators allow us to engage in continuous improvements that allow us to better serve national needs and ensure Congress and the taxpayers that we are effective stewards of public investments.

We are committed to the respon: ible stewardship of the taxpayer's investment in our insti ution. We are actively working to reduce our expenses $w$ herever possible and to structure our internal cost accounting systems to ensure the most cost-effective utilization of our funds and facilities.

Question 2: What are your views on S. 47.3 (Johnston) and H.R. 14.32 (Brown)? What specific benefits might flow from their enactment? What problems arise if they are not enacted? How can Congress value their possible benefits and decide whether these are worth the costs of continuing to fiund the labs at their historic levels?

Response: I unequivocally endorse the intent of Senate Bill 473. The central issue that S. 473 addresses is not the preservation of DOE laboratory employment levels, as some may claim, but rather, how these world-class laboratories can return greater value to the taxpayer by contributing in larger measure to our nation's economic security - and to do so without adversely impacting their more traditional roles in support of DOE:'s military, energy, and environmental security missions. By encouraging more effective utilization of the federal investment in the $\mathrm{DOE}$ laboratories, S. 473 recognizes that we are dealing with a long-term national security issue and that the laboratories should be utilized to their fullest extent, consistent with other mission assignments, to assist the technology leadership of U.S. industry.

Senate Bill 473 reaffirms the importance of the technology transfer mission of the DOE laboratories and targets a number of important technology transfer processes for improvement. Among the notable improvements are streamlining and standardizing the processes for approving cooperative research and development agreements (CRADAs), increasing the flexibility of technology transfer funding, and permitting flexibility to assure the protection of information.

In essence, the bill aims to facilitate maximum exploitation of the dual-use potential of DOE national laboratory technical capabilities. What distinguishes the DOE laboratories is the depth and breadth of their technology base or, in modern terminology, their core competencies. And what most competitiveness issues have in common is a set of scientific and technological underpinnings well matched to the laboratories' core competencies.
With this bill, Congress faces a window of opportunity to foster the long-term tec'inological leadership of U.S. industry.

With respect to House Resolution 1432, Sandia is supportive of the intent of the legislation. The themes of H.R. 14.32, summarized as determining future missions, developing metrics to measure progress, and providing incentives for national laboratories, as well as providing for better coordination among all federal labor itories, are consistent with a Total Quality Management philosophy. However, I do have some specific concerns that I expressed in earlier testimony:

- It is our recommendation that the mission definition of H.R. 1432 be consistent with the historical activities of the DOE multiprogram national laboratories. The mission statement of H.R. 1432 should not be constrained to the point that DOE laboratories cannot contribute in areas where their core competencies can uniquely contribute to national needs. The reaffirmation of our national security mission, broadly defined, would best allow the DOE multiprogram national laboratories to serve the nation.

- I believe that an objective study of the labs would be acceptable. However, the assertion in H.R. 1432 that one or more of the Defense Programs labs must be redirected entirely to a civilian mission is inappropriate and would tend to take objectivity from the study.

- I question the necessity of creating a management infrastructure to manage a set-aside (CRADA) program. Such centralized authority would impede our ability to maximize the dual-use value of our competencies by separating them from the DOE sponsor.

- The reporting requirements in Section 7 for CRADAs signed by $\mathrm{GOCO}$ lab directors are ambiguous. Also, the legislation does not address the regulations for funds spent and committed to support CRADAs signed by the laboratory directors. The ability to sign CRADAs would be meaningless if the lab directors do not have the authority to spend current funds and commit future funds to CRADAs.

- I question the desirability of having a FCCSET committee assign missions to specific laboratories within agencies. FCCSET should arbitrate missions among agencies and let each agency decide how best to utilize its assets.

- The legislation requires DOE to institute Total Quality Management into the management and operation of departmental laboratories. I strongly agree with this provision. I am particularly pleased that Secretary O'Leary is committed to implementing TQM throughout the DOE complex.

- H.R. 1432 would establish the National Technology Partnership Award. This award is an excellent idea, as it 
is too easy to overlook the importance of recognition when applying total quality management principles. We expect that the process of competing for this award will improve the quality programs of all 1$)($ )E program elements and laboratories.

Question 3: Do you support legislation, such as that in the proposed Penny-Kasich amendment, to establish a "lab closing" commission" "analogous to the military base closing commission set up by Congress several years ago? Should some labs be closed or consolidated? (iiven current pressures to reduce the deficit, should congress set a flat or declining overall funding lev if for the labs in coming years?

Response: I do not support the proposal of the P'ennyKasich amendment to create a "lab closing commission." A federal laboratory should close when it can no longer attract federal agency customers and respond effectively to those customers' needs. let the federal agency customers vote with their dollars, rather than convene a special commission to mandate which laboratories ought to close or consolidate.

A taste of market forces within the federal laboratory community might be more useful and healthful for the laboratory community as a whole than creation of a closing commission. Consequently, I support the concept of permitting greater competition among federal laboratories for federal missions. Agencies should be discouraged from creating a protectionist environment for captive laboratories. l.et's make the national laboratories truly national by permitting and encouraging interagency competition for their services. Such competition may result in laboratory growth, decline, or transformation. Weaker laboratories may find they can strengthen their roles by forming strategic alliances . vith other labs in certain areas of expertisc. I think we would see, under this scenario, the growth and consolidation of large, multiprogram federal laboratories with outstanding technical depth and breadth at the expense of smaller, singlepurpose labs that now lack multidisciplinary breadth.

There is no guarantee that a radical restructuring of the DOE laboratory community will result either in improved performance or better value for the taxpayers' dollar. A national laboratory is more than a collection of facilities and people with technical skills. The creative synergy of a multiprogram laboratory environment is established over time and is the result of relationships among technical core competencies that are exercised for the benefit of sponsors' programs. Those competencies may be difficult to reconstruct in another environment or at another time. Therefore, proposals for closing or restructuring the 1$)($ ) laboratories should be considered with great caution.

Question 4: What are the benefits and disadvantages of the various types of collaborations that labs now engage in with private industry, universities, and others? These types of col- laboration indude contract research, cooperative research, workshops/scminars, licensing, sponsored research, techmical consultation, employece exchange', use of lab facilities, individual lab visits, and information dissemination (for example, through journals and other papers). Are there drawbacks to some of these types of techmology transfer which could be remedied by legislation? Should some be emphasized?

Respo:tse: At Sandia we certainly use all of the various vehicles of collaboration with industry mentioned in this question. They each have their individual advantages and drawbacks. We find hat the flexibility to employ all such collaborative tcols, depending on the circumstances, is invaluable.

Generally, the Cooperative Research and Development Agreement (CRADA) is our most successful vehicle for collaboration. Unfortunately, CRAIDAs tend to be small efforts and involve individual companies rather than entire industries. At Sandia, we are working hard to establish large (RAI)As involving industry consortia. I discussed several examples of these consortia (RAI)As in my statement. They have been immensely successful. We believe these larger efforts will have greater impact on an industry as a whole and consequently greater impact on the U.S. producers' market competitiveness.

User facilities have historically been effective vehicles for giving industry access to a small part of the laboratories. More facilities should be designated as user facilities, and the concept should be expanded to include centers of excellence that may not be associated with physical laboratory assets. DOE is working hard to expand the user facility concept along these lines.

Question 5: What are the obstacles to and possible benefits of more partnerships among the labs and private industry? Will a greater focus on commercialization of new technologies turn the labs into "job shops"? Will it create new conflict of interest concerns between the contractor at a GOCO lab and its affiliates who may seek ventures with the lab? Are there competitive concerns? In particular, will "deselected" competitors feel the labs are acting in an anticompetitive fashion if some firms in an industry - but not all - are given the financial edge' of preferential access to the labs' work?

Response: let me begin with the benefits of more partnerships. First, we believe that there is a benefit to U.S. industry and a consequent macroeconomic benefit. (Possible metrics for measuring this benefit were discussed in answer to the first question above.) Collaboration leverages an industry's $R \& D$ ) resources. It produces more robust vendors of high-technology goods and services for government missions and commercial markets. It also exercises and strengthens the national laboratories' core technical competencies.

Now for the obstacles: As I mentioned earlier, the Cooperative Research and Development Agreement (CRADA) is our most successful vehicle for collaborations 
with industry. Unfortunately, the approval process for CRAI)As is still cumbersome and time-consuming. The General Accounting (Office estimated the average approval time at 32 weeks; the Secretary of Energy has pledged to cut that in half. DOE is working hard to achieve that goal. In my view, the goal can be achieved if DOE approves technology transfer activity at the program level and delegates approval authority for individual CRADAs to the laboratories under a block funding arrangement. We at the laboratories are willing to be judged by whatever accountability and performance measures DOE feels would be useful to ensure that block funding is properly administered. As the system stands now, CRADA negotiations do not really get serious until after DOE has indicated funding approval of the specific CRADA. DOE approval at the block funding level would permit CRADA negotiations to move quickly. Strict policies and procedures are in place to mitigate conflict-of-interest concerns with respect to the GOCO contractor. Some of these policies and procedures are contractual. Others are embedded in the general procedures we employ to score and select CRAIDA proposals.

CRADA proposals are scored both for technical merit and commercialization potential. The Technical Area Coordinating Teams that evaluate CRADA proposals comprise representatives from several DOE laboratories and therefore cannot be dominated by the interests of a single lab. The proposals' commercialization plans are evaluated by persons with business education and expertise. If an individual CRADA proposal is not selected, it is because it ranked low in this evaluation process.

I want to stress that, at Sandia, it is not our practice to select one worthy competitor over another worthy competitor for a CRADA project. That is precisely the situation we want to avoid by emphasizing large-scale collaborations involving industry consortia whenever possible. As mentioned in my statement, those arrangements benefit all consortia members equally by sharing the costs and fruits of precompetitive, generic R\&D that is driven by industry-defined road maps. Our consortia CRAI)As have been very successful, and 1 believe they are the model for how the national laboratories should do technology transfer more effectively and with greater impact. This model also is an effective defense against the "job shop" modality that could result from excessive reliance on numerous small-value CRADAs.

I also wish to note that Sandia and the other Defense Programs laboratories conduct a program that assists small businesses that are perhaps unable to compete effectively with the industry heavyweights. CRADAs with small businesses are often $100 \%$ cost-borne by government.

There is one more item I must discuss under this category of "obstacles": that is, the erosion of the science and technology base that underlies the laboratories' excellence and makes technology transfer worthwhile. Historically, the laboratories' core technical competencies have been nourished with a consistent stream of level-ofeffort funding from the nuclear weapons program. As you know, the weapons Ri)\&T (Research, Development, and Testing) budget has been plummeting - something on the order of 10 percent per year. Consequently, the science and technology foundation at the laboratories is jeopardized. If this trend continues, it will weaken our technical foundations, and it would become very difficult to sustain the core competencies in which the national laboratories have demonstrated technical leadership.

Question 6: How much funding-overall, from all sourc - has been made available to the labs in the last few years for cooperative research with private industry? Should this almount be increased? Should the discipline of 50-50 costsharing be strengthened by requiring greater contributions from private industry, for example, 60-40 or 70-30?

Response: The lion's share of funding for cooperative research and development with industry is provided by the DOE Defense Programs Technology Transfer Initiative. In total, for all labs, this funding was $\$ 20$ million in fiscal year 1991; $\$ 50$ million in FY 1992; $\$ 141$ million in FY 1993; and will be approximately \$200 million in FY 1994. The Sandia portions of those amounts are: $\$ 9$ million in FY 1991; \$19 million in FY 1992; \$50 million in FY 1993; and approximately $\$ 85$ million in FY 1994 . This is not "new" money; it does not augment total laboratory effort and employment above our historical levels. It is money that used to fund our nuclear weapons RD\&T work and now is used to commercialize technologies originally developed in the weapons program.

Funds from other DOE programs may also support cooperative research. The extent of this activity at Sandia in FY 1994 is about $\$ 15$ million. So, total DOE funds for cooperative research at Sandia in FY 1994 are approximately $\$ 100$ million.

Cooperative research funding is about 10 percent of our total DOE funding. It should be doubled if we are to meet the target of $20 \%$ set by the Secretary of Energy as a goal for the DOE laboratories. Industry applications for CRADAs are ten times what we can currently accommodate.

You should also be aware that for the vast majority of Sandia CRADAs, industry contributes more than 50 percent of the cost. The 50/50 cost-sharing guideline is flexible under DOE rules, however. As noted in the question above, some small business (RAD)As are 100 percent paid from public funds. At the other end of the spectrum, at least two of Sandia's CRADAs are 100 percent paid by industry. There are cases where the ratio deviates from the 50/50 rule to reflect how the burden of risk is shared. In cases of high technical risk, it may be appropriate for the government to bear a majority of the cost. In cases of low risk, it may be appropriate for industry to bear most of the cost. The 50/50 rule is a good guideline, however, but should remain flexible. 
Question 7: What kind of accounting standards and conventions are used in determining the accuracy and validity of different cost contributions from both the labs and their partners?

Response: As required by the operating contract, Sandia National Laboratories adheres to cost accounting standards (CAS) as promulgated by the Cost Accounting Standards Board and any CAS-related guidance from the Department of Energy. Sandia also submits a detailed Cost Accounting Standards Disclosure Statement to DOE which describes Sandia's accounting practices. In addition to the CAS requirements, Sandia complies with DOE orders regarding financial and accounting management. These orders are based on Generally Accepted Accounting Principles.

The accuracy and validity of Sandia's accounting system and its associated costs are audited by professional audit staffs, ranging from corporate internal auditors, to the DOE Inspector General, to the General Accounting Office. Each of these audit groups follows the Generally Accepted Government Auditing Standards.

The accounting practices of our industry partners vary. However, in evaluating CRADA proposals we are primarily concerned that cost estimates for the industry partner's share of the technical work are reasonable. The Technical Area Coordinating Team evaluating the proposal applies cost estimation principles to satisfy themselves that the proposed cost estimates are reasonable. If the team concludes that the estimates are not reasonable, the proposal will be renegotiated. Once the CRADA is in place, we continue to evaluate the technical contribution of our industrial partner as he performs his responsibilities under the agreement.

CRADAs are not procurements and therefore are not subject to the Federal Acquisition Regulations (FARs) and associated audit requirements. Any CRADA partner that receives other federal funds - for example, DoD funds for research, development, or procurement - is subject to the FARs and audits for the work under contract. Agency auditors such as the Defense Contract Audit Agency (DCAA) have a legitimate interest in assuring that their funds are not applied to a company's DOE CRADA obligation (unless allowed under the DoD rules governing IR\&D). In general, the audit safeguards already exist for those CRADA partners that do perform government contract work.

Question 8: What new technologies have the greatest potential to improve the productivity of our oil, natural gas, coal, and electric utility industries? Which ones can best improve the efficiency of energy distribution and consumption, and limit or remedly acilerse environmental effects of energy use?

Response: (This question is answered in detail in the main body of this statemeni.) 


\begin{tabular}{|c|c|c|}
\hline MS0101 & 1 & A. Narath (20) \\
\hline MS0102 & 2 & J. A. Tegnelia \\
\hline MS0360 & 1000 & A. R. C. Westwood \\
\hline MS0320 & 1010 & P. L. Mattern \\
\hline MS0335 & 1100 & F. L. Vook \\
\hline MS1190 & 1200 & D. L. Cook \\
\hline MS1079 & 1300 & P. S. Peercy \\
\hline MS0321 & 1400 & E. H. Barsis \\
\hline MS0841 & 1500 & D. J. McCloskey \\
\hline MS0336 & 1700 & R. J. Eagan \\
\hline MS0337 & 1800 & A. D Romig, Jr. \\
\hline MS0803 & 1900 & D. L. Crawford \\
\hline MS0513 & 2000 & H. W. Schmitt \\
\hline MS0517 & 2010 & D. W. Doak \\
\hline MS0332 & 2100 & P. J. Eicker \\
\hline MS1070 & 2200 & R. E. Bair \\
\hline MS0509 & 2300 & R. D. Andreas \\
\hline MS0960 & 2400 & J. Q. Searcy \\
\hline 1S0511 & 2500 & Beeler \\
\hline MS0985 & 2600 & hman \\
\hline MS0507 & 2700 & avid \\
\hline MS0630 & 2800 & J. F. Jones, Jr. \\
\hline MS0953 & 2900 & W. E. Alzheimer \\
\hline MS0186 & 3000 & C. E. Emery \\
\hline MS1017 & 3300 & L. R. Clevenger \\
\hline MS1029 & 3500 & R. C. Bonner \\
\hline MS1088 & 3600 & M. G. Robles \\
\hline MS0149 & 4000 & C. P. Robinson \\
\hline MS0455 & 4100 & G. R. Otey \\
\hline MS1380 & 4200 & W. D. Siemens \\
\hline MS1375 & 4400 & L. D. Bertholf \\
\hline MS0131 & 4500 & iss \\
\hline MS0159 & 4520 & J. R. Bode \\
\hline MS1369 & 4700 & J. P. VanDevender \\
\hline MS0463 & 5000 & R. L. Hagengruber \\
\hline MS0467 & 5090 & J. L. Wirth \\
\hline MS0429 & 5100 & W. B. Nickell \\
\hline MS9006 & $j 200$ & E. E. Ives \\
\hline MS9005 & 5300 & J. B. Wright \\
\hline MS0473 & 5400 & H. J. Saxton \\
\hline MS0461 & 5500 & C. A. Yarnall \\
\hline MS0457 & 5600 & D. B. Hayes \\
\hline MS0769 & 5800 & D. S. Miyoshi \\
\hline MS0570 & 5900 & C. W. Childers \\
\hline MS0724 & 6000 & D. L. Hartley \\
\hline MS0701 & 6100 & R. W. Lynch \\
\hline MS0735 & 6200 & D. E. Arvizu \\
\hline MS1337 & 6300 & D. E. Ellis \\
\hline MS0736 & 6400 & N. R. Ortiz \\
\hline MS1143 & 6500 & J. K. Rice \\
\hline MS0726 & 6600 & J. B. Woodard \\
\hline MS1395 & 6700 & P. E. Brewer \\
\hline MS0725 & 6900 & T. O. Hunter \\
\hline & & \\
\hline
\end{tabular}

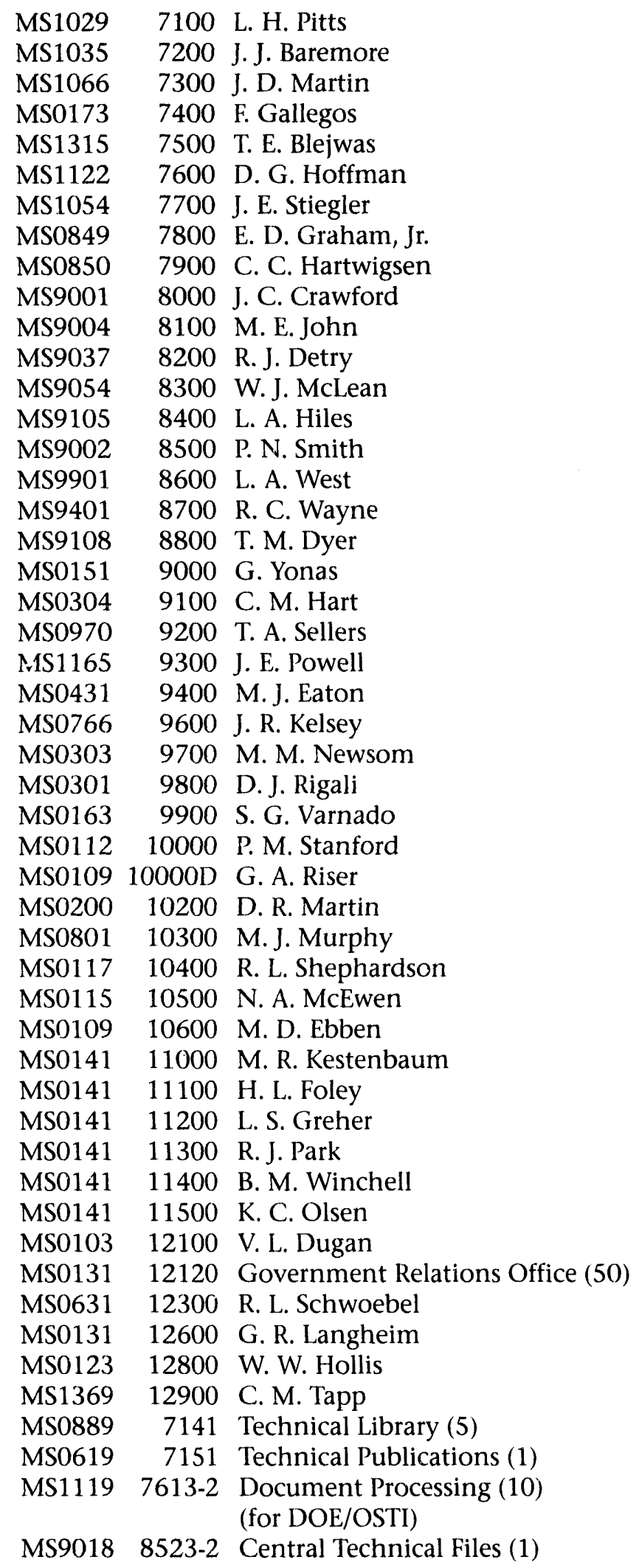



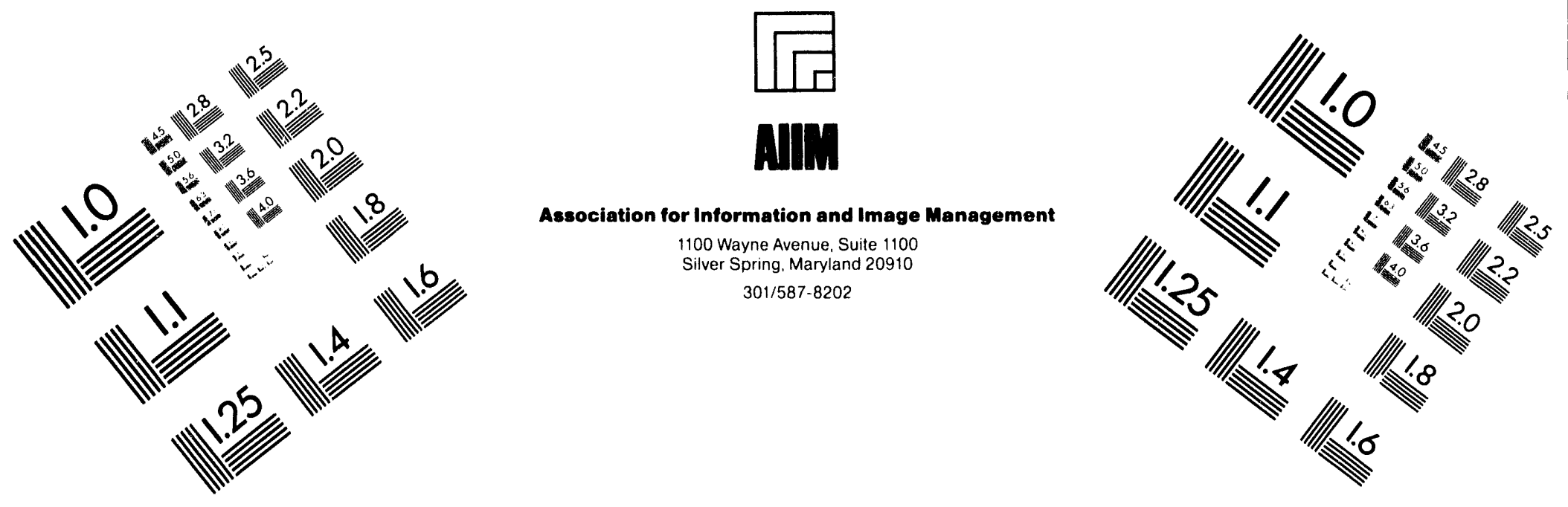

\section{Centimeter}

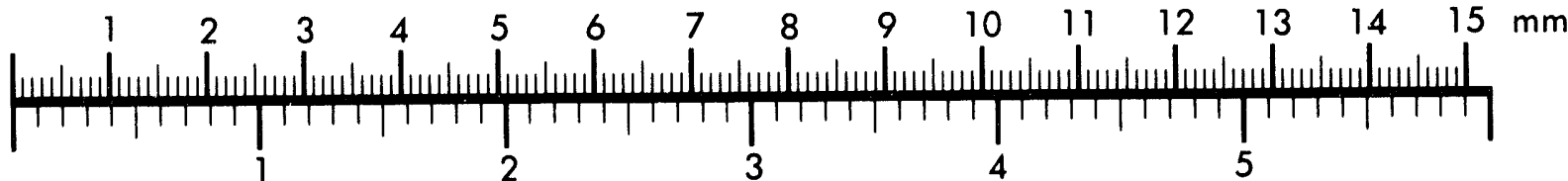
Inches
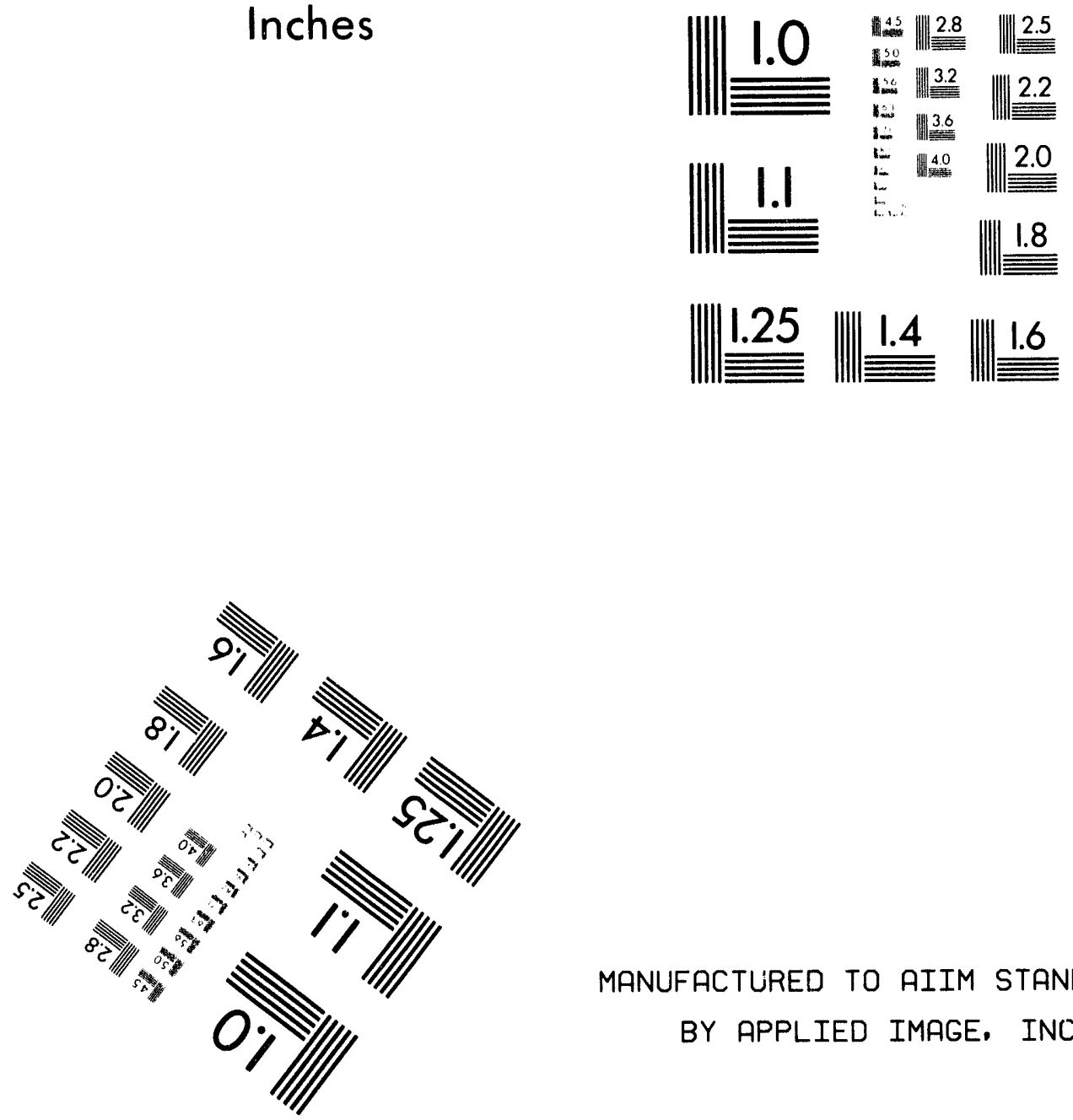

MANUFACTLRED TO AIIM STANDARDS

BY APPLIED IMAGE. INC.

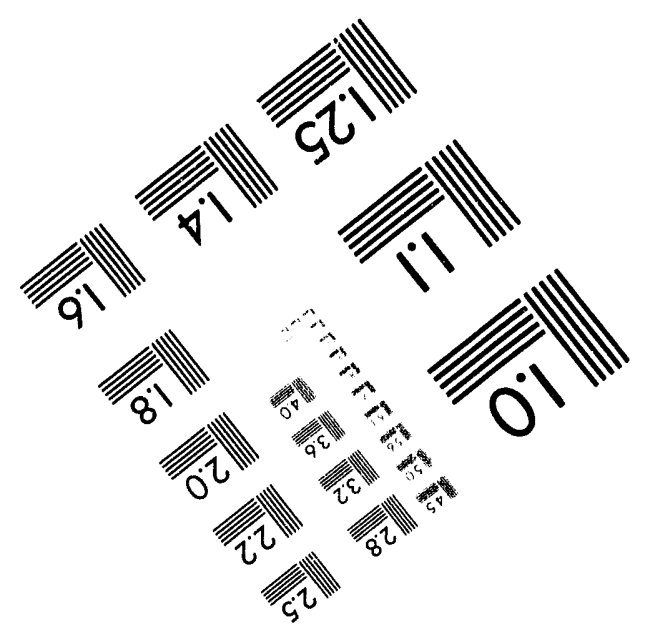




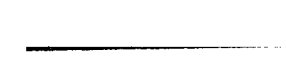



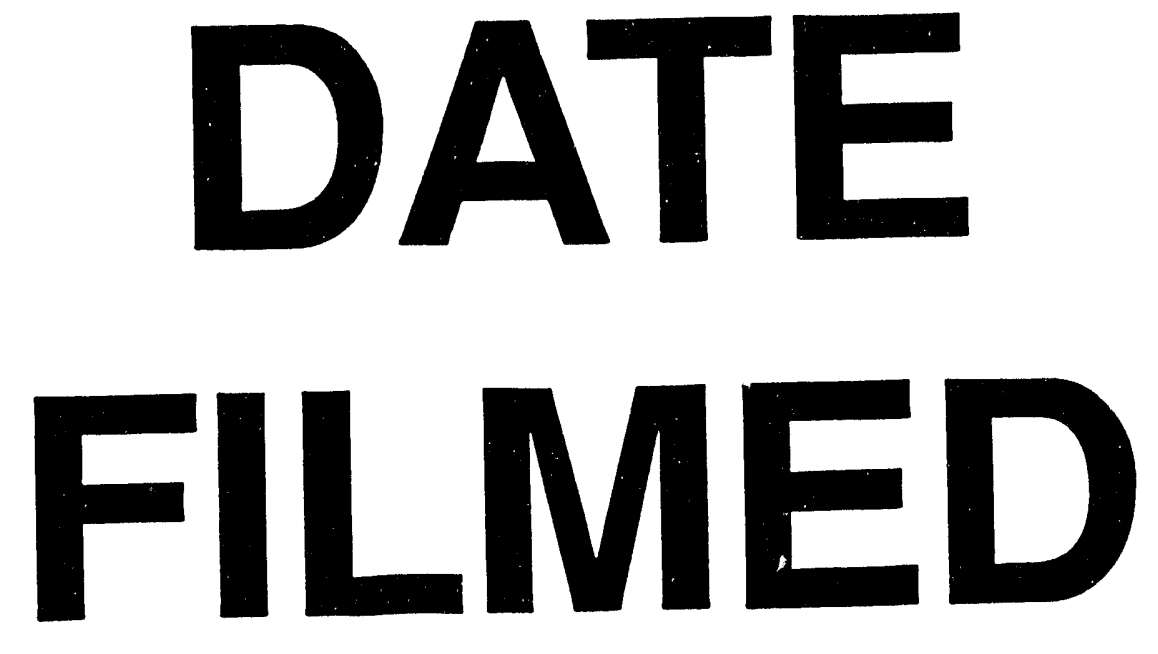

$$
11 / 23 / 94
$$
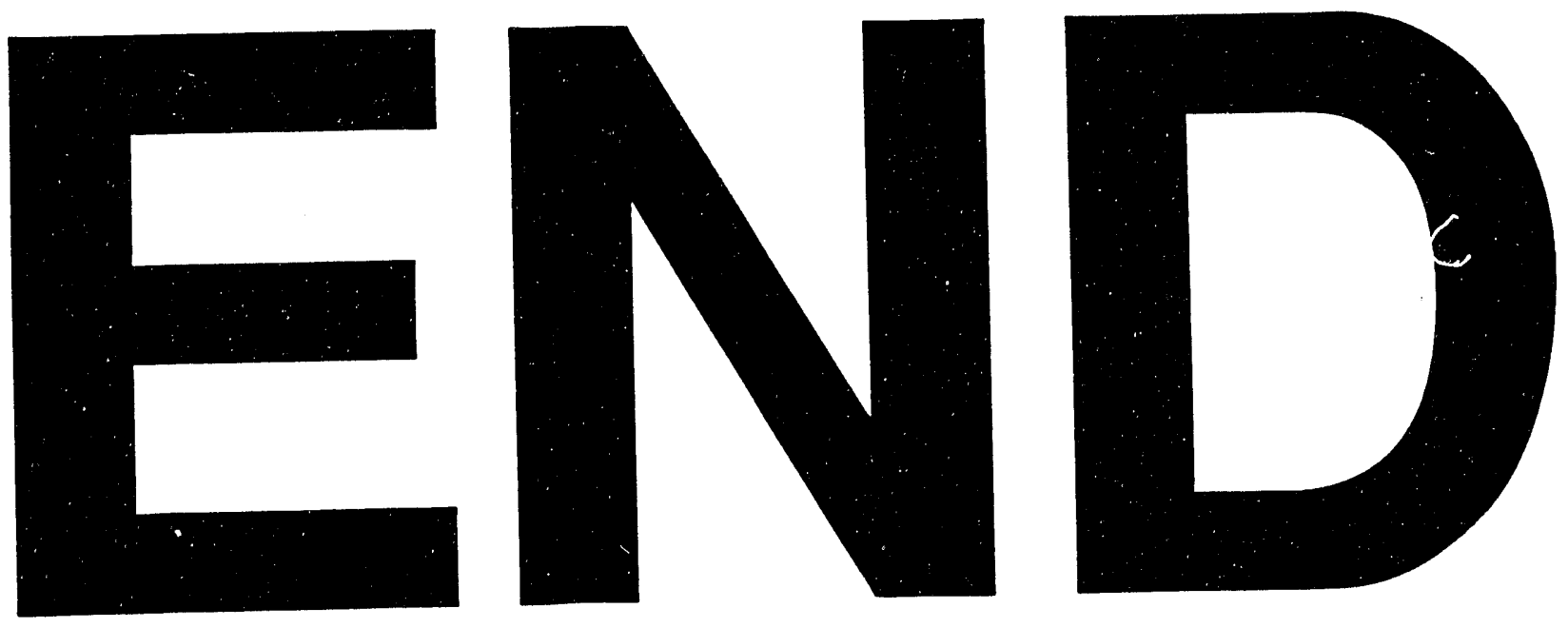